\title{
LITOGEOQUÍMICA E QUÍMICA MINERAL DAS ROCHAS DO MACIÇO CORREAS
}

\author{
LITOGEOCHEMISTRY AND MINERAL CHEMISTRY FROM CORREAS MASSIF ROCKS
}

\author{
Suelen Portughesi da MATA ${ }^{1}$, Antonio Misson GODOY²; Otávio Augusto Ruiz Paccola \\ VIEIRA $^{3}$, George Luiz LUVIZOTTO ${ }^{2}$ \\ ${ }^{1}$ Graduação em Geologia - IGCE- UNESP- Universidade Estadual Paulista. Email: suelenportughesi@ gmail.com \\ ${ }^{2}$ Departamento de Petrologia e Metalogenia- IGCE- UNESP- Universidade Estadual Paulista. Av. 24A, 15151-Bela Vista, CEP. 13 \\ 506-900-Rio Claro (SP), Brasil. Email: mgodoy@rc.unesp.br, george.luvizotto@rc.unesp.br \\ ${ }^{3}$ Pós-Graduação em Geociências- IGCE- UNESP- Universidade Estadual Paulista. Email: otaviovieirageo@ gmail.com
}

\author{
Introdução \\ Materiais e Métodos \\ Geologia Regional \\ Geologia Local \\ Química Mineral \\ Plagioclásio \\ Mica \\ Micas Trioctaédricas \\ Micas Dioctaédricas \\ Litogeoquímica \\ Conclusões \\ Agradecimentos \\ Referências
}

\begin{abstract}
RESUMO - O Maciço Correas está localizado na região sul do estado de São Paulo, relacionado à evolução da granitogênese neoproterozoica na parte norte do Terreno Apiaí e encontra-se intrudido nas rochas encaixantes da sequência metavulcanossedimentar da Formação Água Clara, do Supergrupo Açungui e em rochas do Complexo Granítico Três Córregos. Constitui um stock granítico alongado de $5 \mathrm{~km}^{2}$ na direção ENE-WSW e apresenta mineralizações associadas de cassiterita e volframita. É caracterizado pelas fácies biotita monzogranito porfirítico, biotita-muscovita sienogranito porfirítico, muscovita-zinnwaldita-albita granito porfirítico com topázio e pegmatito. Análises de química mineral sugerem a presença de biotita e muscovita nas fácies graníticas mais antigas e comprovam o caráter sódico dos plagioclásios (albita) e variação na composição das micas, de muscovita a predominantemente zinnwaldita na fácies muscovita-zinnwaldita-albita granito porfirítico com topázio. São rochas peraluminosas pertencentes às séries cálcio-alcalina monzogranítica de alto potássio a shoshonítica a alcalina sódica. O magmatismo é compatível com granito do tipo A, rapakivi, pós-colisional a anorogênico associado a um ambiente intraplaca a um ambiente sin- a pós-colisional de arco magmático, com colocação em estruturas transtensivas correlacionadas à Zona de Cisalhamento Itapirapuã, em ambiente extensional no final do evento colisional da Orogênese Ribeira.

Palavras-Chave: Granito Correas; Geoquímica; Química Mineral.
\end{abstract}

ABSTRACT - The Correas Massif is located in the southern region of São Paulo state, related to the neoproterozoic granitogenesis evolution in the northern part of Apiaí Terrain and intrusive in the surrounding rocks of the Água Clara Formation metavolcanicsedimentary sequence, from Açungui Supergroup and in Três Córregos Granitic Complex rocks. It constitutes an elongated granite stock of $5 \mathrm{~km}^{2}$ in the ENE-WSW direction and presents associated mineralizations of cassiterite and wolframite. It is characterized by the biotite porphyritic monzogranite, biotite-muscovite porphyritic syenogranite, muscovite-zinnwaldite-albite porphyritic granite with topaz and pegmatite facies. Mineral chemistry analyzes reveal the presence of biotite and muscovite in the oldest granite facies and prove the sodium character of plagioclases (albite) and variation in micas composition, from muscovite to predominantly zinnwaldite in the muscovite-zinnwaldite-albite porphyritic granite with topaz facies. These are peraluminous rocks belonging to monzogranitic calcium-alkaline series of high potassium to shoshonitic to sodium alkaline. Magmatism is compatible with A type granite, rapakivi, post-collisional to anorogenic associated with an intraplate environment to a post-collisional magmatic arc environment, with placement in tension structures correlated to the Itapirapuã Shear Zone, in an extensional environment at the end of Ribeira Orogenesis collisional event.

Keywords: Correas Granite; Geochemistry; Mineral Chemistry.

\section{INTRODUÇÃO}

O Granito Correas (Figura 1) está localizado no sudeste do estado de São Paulo, no Bairro Correas, distrito de Itaboa, município de Ribeirão Branco e insere-se na porção norte da Folha Topográfica de Araçaíba (SG-22-X-B-II-3) em escala 1:50.000, do Instituto Brasileiro de Geografia e Estatística.
O reconhecimento e individualização dos corpos graníticos Sguario e Correas ocorreram com o "Projeto Engenheiro Maia (SG. 22-X-B-I2) e Ribeirão Branco (SG.22-X-B-II-1)" por Theodorovicz et al. (1986), a partir do mapeamento geológico sistemático na escala 1:50.000, realizado pela Companhia de Pesquisa 
e Recursos Minerais em convênio com a Secretaria da Industria e Comércio Ciência e Tecnologia do Estado de São Paulo e que resultou na divulgação do mapeamento destas folhas por Theodorovicz et al. (1988).

Com a descoberta da mineralização de cassiterita pelo Instituto de Pesquisas Tecnológicas (IPT) e sob o patrocínio do Governo do Estado pelo Programa de Desenvolvimento de Recursos Minerais - Pró-
Minério, iniciou-se em meados de 1986, a primeira etapa da pesquisa mineral na área do Maciço Correas, que resultou na identificação e caracterização específica do minério da jazida do Bairro dos Correas.

A jazida corresponde a um depósito polimetálico de $\mathrm{Sn}, \mathrm{W}, \mathrm{Zn}, \mathrm{Cu}$ e $\mathrm{Pb}$, no qual a mineralização de cassiterita e volframita encontra-se associada principalmente a veios, bolsões, stockworks de quartzo e greisens.

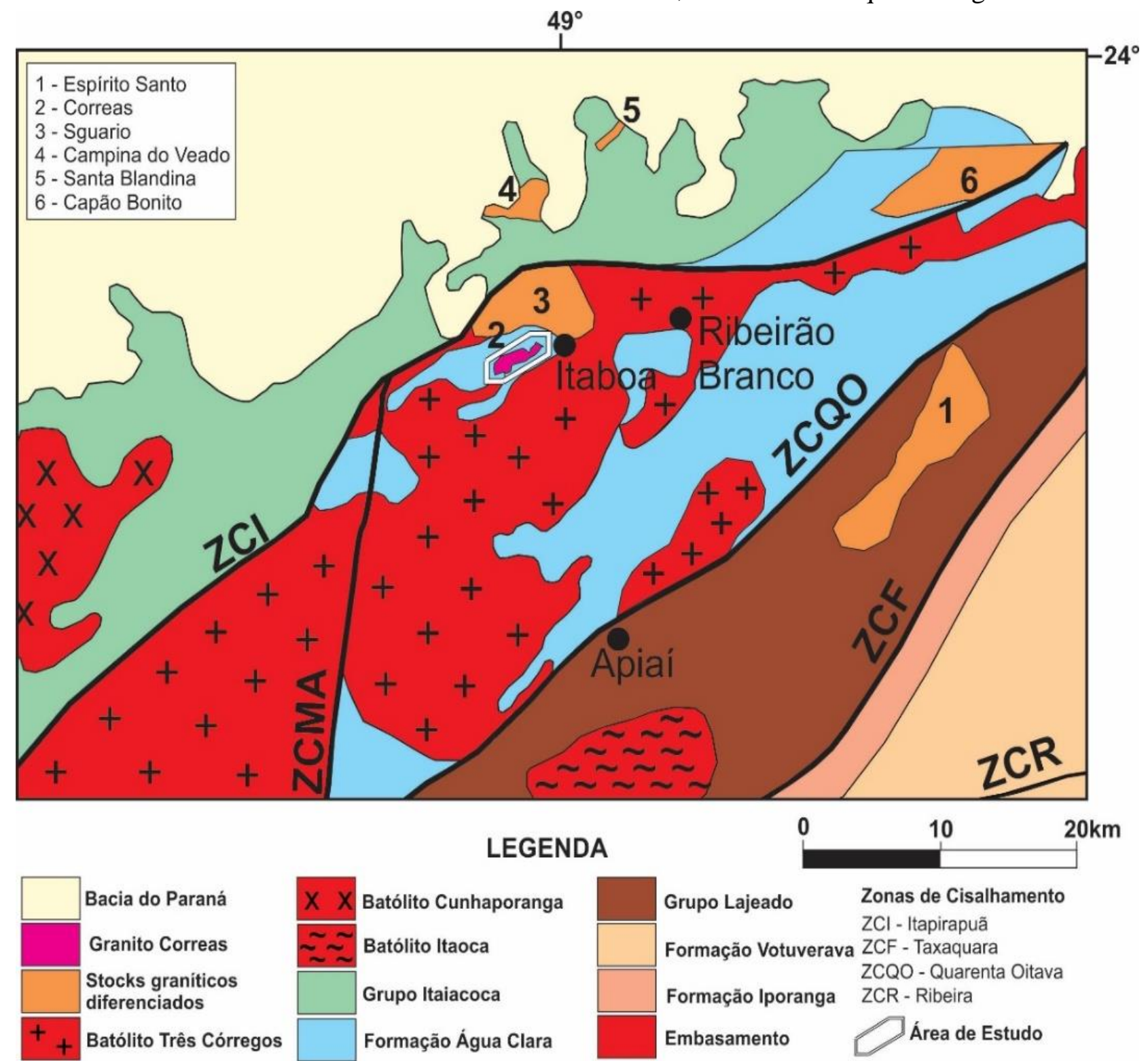

Figura 1 - Mapa Geológico do Terreno Apiaí com a disposição dos principais corpos graníticos e localização da área de estudo do maciço Correas. Modificado de Prazeres Filho (2005).

A partir destes trabalhos iniciais, inúmeros artigos direcionados a mapeamentos, petrografia geoquímica e especificamente com enfoque a ocorrência mineral, foram elaborados por membros da equipe foram elaborados como Silva \& Etchebehere (1986); Goraieb et al. (1987; 1988); Goraieb \& Oliveira, (1990); Silva \& Pressinotti (1991); Pressinotti et al. (1992);
Pereira et al. (2001, 2003, 2008) e trabalhos de dissertações e teses de Goraieb $(1995,2001)$ e Silva (1995). Trabalhos atuais envolvendo especificamente a petrogênese das rochas graníticas deve-se a Mata (2019) e Mata et al. (2020). Trabalhos geoquímicos e geocronológicos das rochas do Granito Correas devemse inicialmente a Gimenez Filho (1993), que 
obteve para a fácies biotita granito pelo método de K-Ar em biotita, idade de $564 \pm 19$ Ma e, para a fácies biotita-muscovita granito, pelo método de $\mathrm{Rb}-\mathrm{Sr}$ em rocha total, idade de $480 \pm 19 \mathrm{Ma}$. Goraieb (1995) obteve para a fácies biotitamuscovita granito, pelo método $\mathrm{Rb}-\mathrm{Sr}$ em rocha total, idade de $603 \pm 7 \mathrm{Ma}$. Goraieb (2001), para a fácies albita granito obteve duas idades: uma em U-Pb (zircão e monazita) de $601 \pm 11$ e a outra de $619 \pm 11$ Ma. Prazeres Filho (2005) pelo método de U-Pb (zircão), obteve a idade $590 \pm 2$ Ma para a fácies biotita granito.

Este conjunto de rochas graníticas está associado a ambientes extensionais tardios de arco magmático e constitui um dos últimos

eventos magmáticos acrescionários neoproterozoicos que se encontram associados a Orogenia Ribeira (Almeida et al., 1977).

A necessidade constante na atualização de dados geológicos, geoquímicos e de química mineral permite a adequação atual da composição química e da variação química dos minerais. O objetivo deste trabalho é ampliar o conhecimento sobre essa sequência magmática, a partir de novos dados, de modo a caracterizar este magmatismo do tipo A rapakivítico, que registra e identifica um importante processo magmatogênico e constitui o último evento de acresção associado a deformação regional tardia de natureza rúptil.

\section{MATERIAIS E MÉTODOS}

As análises laboratoriais das rochas do maciço Correas foram feitas nos laboratórios do Departamento de Petrologia e Metalogenia (DPM), Universidade Estadual Paulista "Júlio de Mesquita Filho" (Unesp) - Campus de Rio Claro.

As análises químicas qualitativas e semiquantitativas foram realizadas no Laboratório de Microscopia Eletrônica, utilizando-se Microscópico Eletrônico de Varredura (MEV) modelo JEOL-JSM-6010LA, com detector de EDS (Energy Dispersive X-Ray Spectrometer) acoplado.

Análises químicas quantitativas foram realizadas no Laboratório de Microssonda Eletrônica por microssonda eletrônica da marca JEOL modelo JXA-8230 Superprobe, acoplado a 5 detectores de WDS (Wavelenght Dispersive X-Ray Spectrometer), sob condições de $15 \mathrm{kV}$, aceleração de 20,4 nÅ e diâmetro do feixe de $10 \mu \mathrm{m}$, com padrões naturais para todos os elementos em minerais silicáticos formadores de rocha. Foram analisados cristais de plagioclásio, feldspato potássico e mica (biotita, zinnwaldita e muscovita), escolhidos por critérios petrográficos de acordo com a mineralogia de interesse e as micas prioritárias das fácies.

As análises químicas de rocha total e multielementar para elementos maiores, menores, traços e elementos terras raras (ETR), foram realizadas no Laboratório de Geoquímica (LABOGEO), sendo utilizada fluorescência de raios $\mathrm{X}$ para os elementos maiores (concentração em \%), através de pastilha fundida em meio borato e para os elementos menores e traços (concentração em ppm), através de pastilha prensada.

Para a determinação dos elementos terras raras (em ppm) foi utilizada espectrometria de emissão atômica por plasma indutivamente acoplado (Inductively Coupled Plasma-Atomic Emission Spectrometry - ICP-AES), segundo os padrões de rotina do laboratório (Malagutti et al., 1998).

\section{GEOLOGIA REGIONAL}

A área insere-se na Província Mantiqueira Central (Almeida, 1967; Almeida et al., 1981; Hasui \& Oliveira, 1984; Heilbron et al., 2004), na faixa sul do Cinturão Ribeira (Cordani et al., 1973; Almeida et al., 1977; Hasui et al., 1978; Hasui, 2010; Hasui, 2012) ou no Cinturão de Dobramentos Sudeste (Cordani et al., 2000).

O Cinturão Ribeira é caracterizado na área pelo Terreno Apiaí (Hasui, 2010; Hasui, 2012) que é separado por zonas de cisalhamento transcorrentes destrais (Campanha, 1991; Campanha, 2002; Campanha \& Sadowski, 1999; Heilbron et al., 2004; Faleiros, 2008; Faleiros et al., 2010; Faleiros et al., 2011; Santos et al.,
2015). O Terreno Apiaí consiste em sequências supracrustais de baixo a médio grau metamórfico, designadas como Grupo Açungui (Almeida, 1957; Petri \& Suguio, 1969; Fiori, 1990), e posteriormente proposto como Supergrupo Açungui (Campanha, 1991; Campanha \& Sadowski, 1999) de idade mesoproterozoica a ediacarana por Tassinari et al. (1990), Fiori $(1992,1994)$ e teve a divisão estratigráfica na área proposta em uma unidade litotectônica principal denominada de Formação Água Clara.

A evolução do Terreno Apiaí remonta às sequências metassedimentares de idades meso-e 
neoproterozoica que foram acrescidas como um terreno durante o Neoproterozoico (Faleiros, 2008). Acredita-se que as sequências mesoproterozoicas desses terrenos registrem uma história metamórfica e de deformação anterior a instalação das bacias neoproterozoicas, apresentando em geral um metamorfismo na fácies xisto verde médio a anfibolito (Heilbron et al., 1995; Heilbron et al., 2004; Faleiros, 2008; Campanha et al., 2015).

A Formação Água Clara é subdividida em dois termos informais principais: (I) Unidade de Xistos, dominada por litotipos silicáticos como mica xisto, quartzo-mica xisto e xisto carbonático, apontando para origem em ambiente marinho profundo; e (II) Unidade Carbonática, composta por rochas calciossilicáticas e mármore calcítico puro a impuro, originada em domínio de plataforma continental rasa (Fiori, 1990; Fiori, 1994; Kops, 1994; Frascá et al., 1990).

Destas unidades reconheceu-se em campo um pacote de filitos sericíticos a quartzosos com intercalações de metacalcários (mármore, metacalcário e metacalciossilicatada) (Mata et al., 2020). O estudo dos granitoides orogênicos a anorogênicos da Faixa de Dobramento Ribeira foi inicialmente proposta por Hasui et al. (1978) e Janasi \& Ulbrich (1992), que individualizaram os inúmeros corpos graníticos do estado de São Paulo. No Neoproterozoico houve retomada do sistema distensivo, isso possibilitou manifestações magmáticas e rifteamentos que evoluíram para margens passivas, seguido de um episódio de convergência, formando os granitoides pré- a tardi- tectônicos Três Córregos (Fuck et al., 1967).
Estes batólitos são constituídos por granodioritos a monzogranitos cálcio-alcalinos de médio a alto potássio mais antigos, formados entre 630 e $605 \mathrm{Ma}$ (idades U-Pb em zircão) em um ambiente de margem ativa (Guimarães, 2000; Prazeres Filho et al., 2003) e foram subdividido por Prazeres Filho (2005) em sete unidades graníticas, a saber: Paina, Apiaí-Guaçu, Santa Bárbara, Arrieiros-Cerro Azul, Conceição, São Sebastião e Barra do Chapéu-Ribeirão Branco.

Esta última é a mais representativa na área de estudo e apresenta stocks graníticos tardios de diferentes dimensões, constituindo porções mais jovens de monzogranitos a sienogranitos metaluminosos, sendo estes formados durante um período pré-colisional entre 620 e $590 \mathrm{Ma}$, como é o caso do Granito Correas e Sguario (Theodorovicz et al., 1986; Theodorovicz et al., 1988; Prazeres Filho et al., 2003)

A granitogênese pós-orogênica a anorogênica engloba corpos circunscritos, tardi-colisionais a pós-colisionais, com idades de 600 a $550 \mathrm{Ma}$, e incluem variedades pós tectônicas, subalcalinas (tipo-A) e variedades alcalinas e shoshoníticas (Bittencourt \& Nardi, 1993), como o Granito Capão Bonito, Campina do Veado, Santa Blandina e Correas, em níveis crustais mais rasos, representando o início da extensão crustal, associada à um processo de escape tectônico com reativações de inúmeras zonas de cisalhamento transcorrentes que seriam responsáveis pela movimentação e posicionamento final dos blocos crustais (Godoy, 1989; Godoy, 2003) e constituem em parte o Cinturão Rapakivi Itu definido por Vlach et al. (1990) ou a Província Rapakivi Itu por Wernick et al. (1997 e 2000).

\section{GEOLOGIA LOCAL}

O Maciço Correas possui dimensões de um stock granítico de $5 \mathrm{~km}^{2}$ com forma elipsoidal alongada e é subparalelo a direção NE-SW da Zona de Cisalhamento Itapirapuã (Figura 2), localizado a sudoeste da cidade de Ribeirão Branco e mais localmente a oeste do distrito de

Itaboa. Este corpo está associado a ocorrência de greisens mineralizados em cassiterita e volframita, observada na lavra da Empresa Minerais e Metais Comércio e Indústria Ltda., que está localizada no extremo nordeste do corpo.

As rochas são intrusivas nos litotipos da sequência metassedimentar do Supergrupo Açungui na Formação Água Clara, constituída na área por quartzito e quartzo-mica xisto; e em hornblenda-biotita monzogranito porfirítico do Complexo Granítico Três Córregos. Além do Maciço Correas, na área ocorrem outros corpos diferenciados tardios como os Granito Sguario, Campina do Veado e Santa Blandina.

O Maciço Correas compreende tipos petrográficos leucocráticos agrupados segundo fácies e/ou associações de fácies: biotita monzogranito porfirítico, biotita-muscovita sienogranito porfirítico, mica-albita granito porfirítico com topázio e uma fase pegmatítica. As texturas que aparecem com maior frequência são as porfiríticas, podendo apresentar texturas rapakivi viborgíticas, 
termos equi- a inequigranulares, piterlíticos ou não podem ocorrer, aplíticos e pegmatoides também são comuns.

A fácies biotita monzogranito porfirítico, a mais antiga, é identificada na porção sudoeste do maciço e aflora sob a forma de um corpo circular, apresentando frequentemente afloramentos na forma de blocos de dimensões variáveis $(\sim 1,5 \mathrm{~m}$ de diâmetro), muitas vezes alterados. São rochas de coloração cinza a rósea, leucocráticas, isotrópicas, inequigranulares a porfiríticas e com fenocristais em sua maioria de microclínio, que variam em torno de $1 \mathrm{~cm}$, fenocristais de quartzo globular que variam de 1 a $4 \mathrm{~mm}$ e cristais de plagioclásio fortemente saussuritizados que variam de 0,2 a $0,5 \mathrm{~cm}$. A granulação da matriz varia de fina a média $(0,2$ a $1 \mathrm{~mm})$. O mineral máfico identificado restringe-se a biotita.

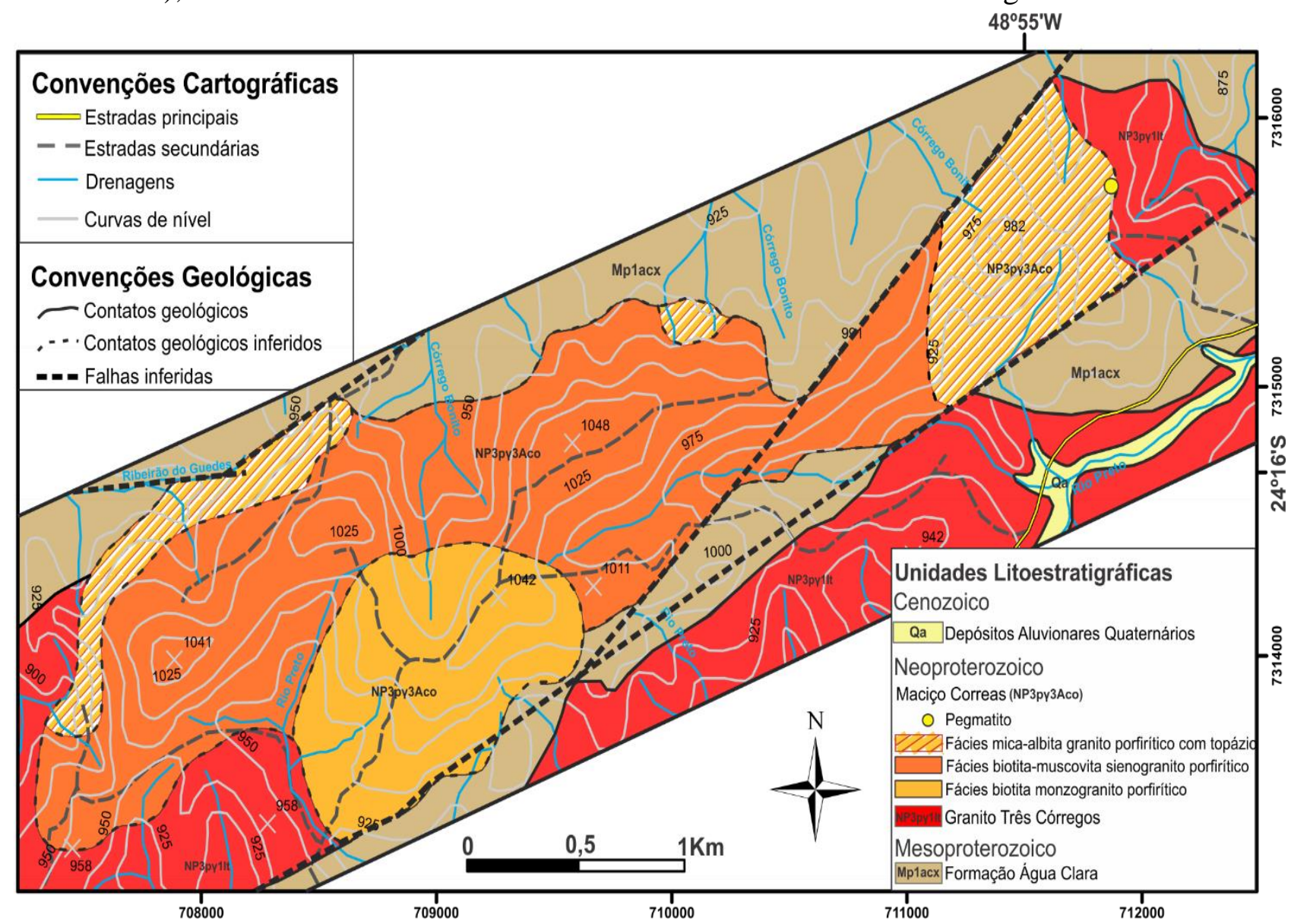

Figura 2 - Mapa Geológico da região do Maciço Correas (Mata, 2019; Mata et al., 2020).

A fácies biotita-muscovita sienogranito porfirítico é a de maior área de expressão no maciço, aflorando em quase toda a extensão do corpo. Possui forma alongada de direção NE-SW e sua ocorrência se dá na forma de blocos de dimensões variáveis, que chegam a até $4 \mathrm{~m}$ de diâmetro, geralmente muito alterados.

A rocha possui coloração rósea a avermelhada, é leucocrática, de estrutura, porfirítica, no qual os fenocristais são de microclínio (1 a $1,5 \mathrm{~cm})$, plagioclásio $(2 \mathrm{a} 6 \mathrm{~mm})$ e quartzo (1 a $5 \mathrm{~mm}$ ) em uma matriz fina a média. Nessa fácies, além da biotita, também há ocorrência de muscovita primária, e de muscovita secundária formada a partir dos processos de alteração hidrotermal.

A associação de fácies mica-albita granito porfirítico com topázio é a de menor ocorrência, e aflora somente nas bordas NE e SW do corpo, sendo atualmente a ocorrência NE lavrada para refratários e cerâmica. É a fácies mais evoluída e mais jovem do maciço e está associada com as mineralizações de $\mathrm{Sn}$ e $\mathrm{W}$ em greisen que ocorrem nas rochas encaixantes próximas a seu contato. Nesta associação ocorrem rochas hololeucocráticas, com ausência de biotita, coloração branca a rósea clara, estrutura maciça, textura inequigranular a porfirítica, com fenocristais de quartzo globular, e microclínio que variam de 3 a $7 \mathrm{~mm}$ em matriz fina a média de 0,1 a $0,8 \mathrm{~mm}$. Podem ser reconhecidas 3 fácies, que se diferenciam principalmente pela coloração e composição mineralógica.

Uma de coloração branca com fenocristais de 
quartzo globular e com zinnwaldita; uma segunda de coloração rósea, com fenocristais de quartzo globular e sem ocorrência de micas; e uma terceira de coloração levemente rósea, também com fenocristais de quartzo e com mica branca (muscovita). Apesar dessas diferenças, na escala de mapeamento, não é possível fazer a distinção. Os pegmatitos e veios são restritos e afloram próximo a fácies mica-albita granito, no contato com as encaixantes. Foram observados alguns afloramentos restritos nos cortes da antiga cava da mineração, e em blocos próximos a esses afloramentos. Os pegmatitos possuem estrutura bandada e caracterizam-se pela alternância de bandas quartzosas e micáceas, com presença de topázio em alguns locais. Os cristais de quartzo, mica e topázio estão bem formados e chegam a ter mais de $5 \mathrm{~cm}$.

A evolução geológica é determinada pelo arranjo tectônico-metamórfico neoproterozoico, que é definido por três fases de deformacionais.

Os dois eventos iniciais são relacionados a tectônica tangencial, ligados à fase colisional, e consequente espessamento de massas crustais e a colocação e deformação das rochas sincolisionais do Complexo Três Córregos.

A deformação posterior é marcada por tectônica transcorrente/transpressiva de alto ângulo que ocorre associada à ascensão magmática tardia e a atual estruturação alongada do granito pós-colisional Maciço Correas.

O metamorfismo regional progressivo é do tipo Barroviano, com rochas em fácies xisto verde alto, com ocorrências locais de metamorfismo de contato e o dinâmico que apresentam natureza retrometamórfica. Maiores detalhes da geologia e petrografia da área são encontrados em Mata (2019) e Mata et al. (2020).

\section{QUÍMICA MINERAL}

O estudo de química mineral do Granito Correas foi desenvolvido principalmente na fácies mica-albita granito porfirítico com topázio, e os principais minerais essenciais caracterizados a partir de microscopia eletrônica de varredura são o plagioclásio (albita) e as micas (muscovita, zinnwaldita).

Também foram analisados alguns cristais de mica (biotita e muscovita) e plagioclásio nas fácies biotita monzogranito porfirítico e biotitamuscovita sienogranito porfirítico.

\section{Plagioclásio}

Foram analisados 13 cristais de plagioclásio nas amostras CR-42 (fácies biotita-muscovita sienogranito porfirítico) e nas amostras CR-17,

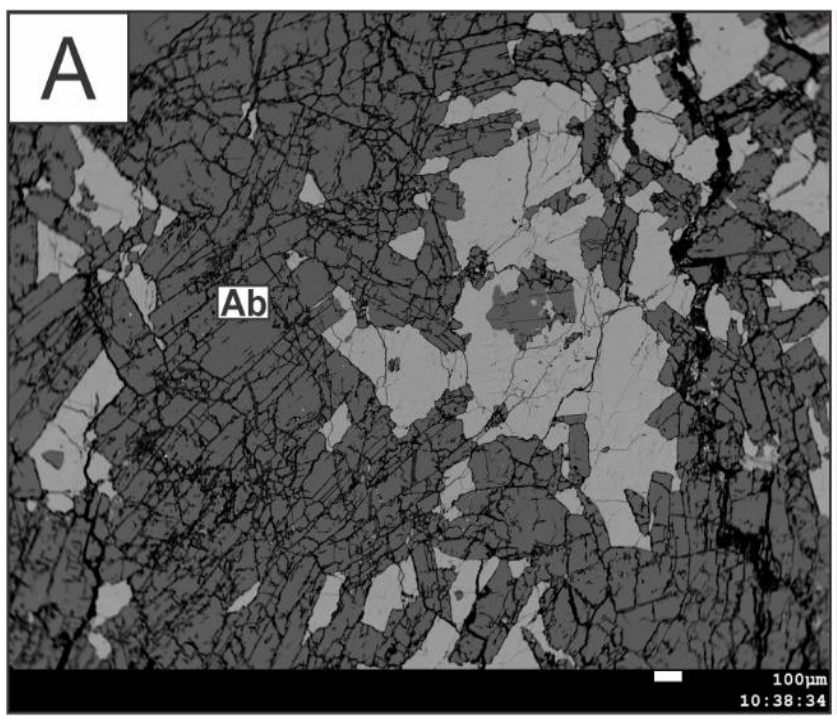

CR-27a, CR-27b e CR-28 (fácies mica-albita granito porfirítico com topázio).

O conteúdo de átomos por unidade de fórmula (a.p.u.f.), para os cristais de plagioclásio analisados de cada amostra foram calculados na base de 8 oxigênios e estão apresentadas na tabela 1 . Na figura 3 de imagem de microscópio eletrônico de varredura (elétrons retroespalhados). Correspondente a fácies mica albita granito porfirítico com topázio, em que são observados cristais de plagioclásio, que apresentam variações composicionais com respeito ao teor de albita entre $A b_{96,69}-A_{b_{99,64}}$ (Figura 4, Tabela 1). Nas demais fácies não foram feitas análises nos plagioclásios.

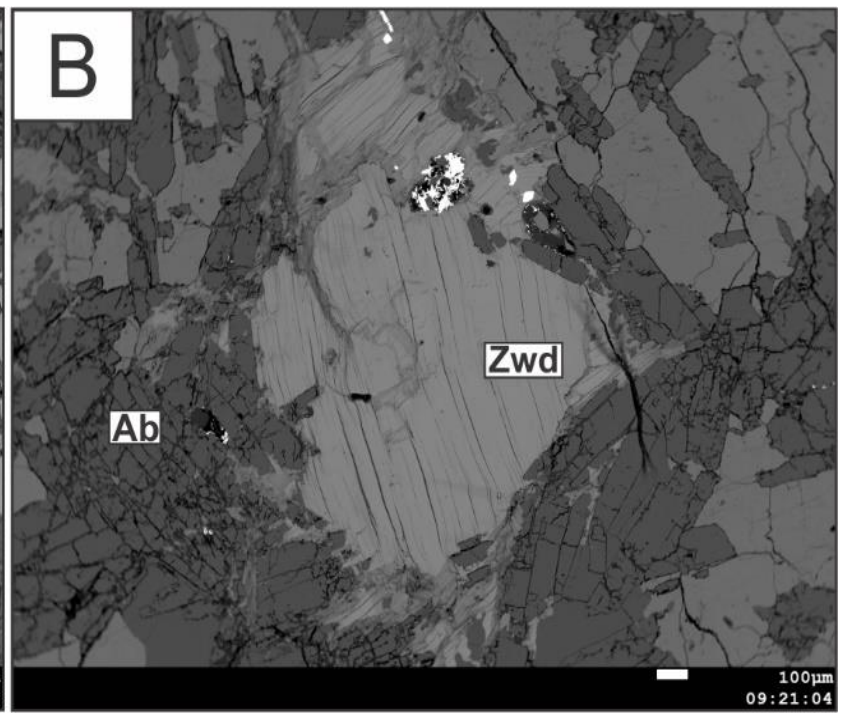

Figura 3 - Imagem de microscópio eletrônico de varredura (elétrons retroespalhados) do mica-albita granito porfirítico com topázio. A) Aglomerados de cristais de albita; B) Cristal de zinnwaldita ao lado de cristais de albita. 


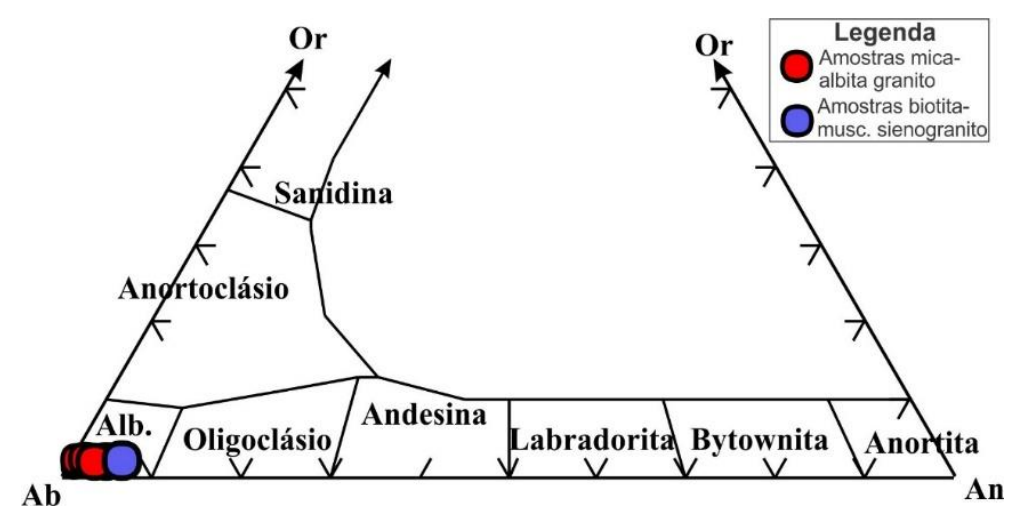

Figura 4 - Diagrama de classificação de feldspatos (Deer et al., 1963). Azul: amostra CR-42. Vermelho: amostras CR17, CR-27a, CR-27b e CR-28.

Tabela 1 - Análises químicas representativas de albita.

\begin{tabular}{|c|c|c|c|c|c|c|c|c|c|c|c|c|c|}
\hline Amostra & CR-28 & CR-28 & CR-28 & CR-28 & CR-17 & CR-17 & CR-17 & CR-17 & CR-17 & CR-17 & CR-27a & CR-27a & CR-27a \\
\hline Cristal & 2 & 2 & 3 & 3 & 1 & 1 & 2 & 2 & 3 & 3 & 1 & 1 & 2 \\
\hline $\mathrm{SiO}_{2}$ & 66,2 & 66,6 & 66,8 & 66,5 & 66,6 & 65,9 & 66,7 & 66,6 & 66,5 & 66,6 & 66,5 & 66,8 & 67,1 \\
\hline $\mathrm{TiO}_{2}$ & 0,0 & 0,0 & 0,0 & 0,0 & 0,0 & 0,0 & 0,0 & 0,0 & 0,0 & 0,0 & 0,0 & 0,0 & 0,0 \\
\hline $\mathrm{Al}_{2} \mathrm{O}_{3}$ & 20,0 & 19,7 & 19,8 & 19,7 & 19,8 & 19,6 & 19,8 & 19,6 & 19,5 & 20,0 & 19,7 & 20,0 & 19,4 \\
\hline $\mathrm{Fe}_{2} \mathrm{O}_{3}$ & 0,0 & 0,0 & 0,0 & 0,0 & 0,0 & 0,0 & 0,0 & 0,0 & 0,0 & 0,0 & 0,0 & 0,0 & 0,0 \\
\hline $\mathrm{BaO}$ & 0,0 & 0,0 & 0,0 & 0,0 & 0,0 & 0,0 & 0,0 & 0,0 & 0,0 & 0,0 & 0,0 & 0,0 & 0,0 \\
\hline $\mathrm{CaO}$ & 0,2 & 0,0 & 0,0 & 0,0 & 0,1 & 0,0 & 0,1 & 0,2 & 0,2 & 0,3 & 0,1 & 0,2 & 0,0 \\
\hline $\mathrm{Na}_{2} \mathrm{O}$ & 11,6 & 11,3 & 11,6 & 11,3 & 11,2 & 11,3 & 11,4 & 11,4 & 11,3 & 11,3 & 11,2 & 11,6 & 11,4 \\
\hline $\mathrm{K}_{2} \mathrm{O}$ & 0,1 & 0,1 & 0,1 & 0,1 & 0,1 & 0,1 & 0,1 & 0,1 & 0,1 & 0,1 & 0,1 & 0,1 & 0,1 \\
\hline Total & 98,1 & 97,8 & 98,3 & 97,6 & 97,8 & 96,9 & 98,2 & 98,0 & 97,6 & 98,4 & 97,7 & 98,6 & 97,9 \\
\hline APUF & & & & & & & & & & & & & \\
\hline Si & 3,0 & 3,0 & 3,0 & 3,0 & 3,0 & 3,0 & 3,0 & 3,0 & 3,0 & 3,0 & 3,0 & 3,0 & 3,0 \\
\hline Al IV & 1,1 & 1,0 & 1,0 & 1,0 & 1,0 & 1,0 & 1,0 & 1,0 & 1,0 & 1,0 & 1,0 & 1,0 & 1,0 \\
\hline $\mathrm{Fe}_{2} \mathrm{O}_{3}$ & 0,0 & 0,0 & 0,0 & 0,0 & 0,0 & 0,0 & 0,0 & 0,0 & 0,0 & 0,0 & 0,0 & 0,0 & 0,0 \\
\hline BaO & 0,0 & 0,0 & 0,0 & 0,0 & 0,0 & 0,0 & 0,0 & 0,0 & 0,0 & 0,0 & 0,0 & 0,0 & 0,0 \\
\hline $\mathrm{CaO}$ & 0,0 & 0,0 & 0,0 & 0,0 & 0,0 & 0,0 & 0,0 & 0,0 & 0,0 & 0,0 & 0,0 & 0,0 & 0,0 \\
\hline $\mathrm{Na}_{2} \mathrm{O}$ & 1,0 & 1,0 & 1,0 & 1,0 & 1,0 & 1,0 & 1,0 & 1,0 & 1,0 & 1,0 & 1,0 & 1,0 & 1,0 \\
\hline $\mathrm{K}_{2} \mathrm{O}$ & 0,0 & 0,0 & 0,0 & 0,0 & 0,0 & 0,0 & 0,0 & 0,0 & 0,0 & 0,0 & 0,0 & 0,0 & 0,0 \\
\hline $\mathbf{A b}$ & 98,5 & 99,3 & 99,6 & 99,3 & 98,9 & 99,6 & 98,8 & 98,6 & 98,7 & 97,9 & 99,1 & 98,6 & 99,6 \\
\hline Anor & 1,0 & 0,2 & 0,0 & 0,1 & 0,6 & 0,0 & 0,5 & 0,8 & 0,9 & 1,6 & 0,5 & 1,0 & 0,0 \\
\hline Or & 0,5 & 0,6 & 0,4 & 0,6 & 0,5 & 0,4 & 0,7 & 0,6 & 0,5 & 0,5 & 0,5 & 0,4 & 0,4 \\
\hline Amostra & CR-27a & CR-27a & CR-27a & CR-27b & CR-27b & CR-27b & CR-27b & CR-27b & CR-27b & CR-42 & CR-42 & \multicolumn{2}{|c|}{ CR-42 } \\
\hline Cristal & 2 & 3 & 3 & 1 & 1 & 2 & 2 & 3 & 3 & 1 & 1 & \multicolumn{2}{|c|}{1} \\
\hline$\overline{\mathrm{SiO}_{2}}$ & 67,1 & 66,2 & 65,9 & 66,1 & 66,1 & 65,8 & 66,7 & 66,1 & 66,0 & 65,7 & 65,1 & \multicolumn{2}{|c|}{64,9} \\
\hline $\mathrm{TiO}_{2}$ & 0,0 & 0,0 & 0,0 & 0,0 & 0,0 & 0,0 & 0,0 & 0,0 & 0,0 & 0,0 & 0,0 & \multicolumn{2}{|c|}{0,0} \\
\hline $\mathrm{Al}_{2} \mathrm{O}_{3}$ & 19,8 & 20,0 & 20,0 & 19,7 & 19,7 & 19,8 & 19,8 & 19,8 & 19,9 & 19,7 & 20,1 & \multicolumn{2}{|c|}{20,2} \\
\hline $\mathrm{Fe}_{2} \mathrm{O}_{3}$ & 0,0 & 0,0 & 0,0 & 0,0 & 0,0 & 0,0 & 0,0 & 0,0 & 0,0 & 0,0 & 0,0 & \multicolumn{2}{|c|}{0,0} \\
\hline $\mathrm{BaO}$ & 0,0 & 0,0 & 0,0 & 0,0 & 0,0 & 0,0 & 0,1 & 0,0 & 0,0 & 0,0 & 0,0 & \multicolumn{2}{|c|}{0,0} \\
\hline $\mathrm{CaO}$ & 0,1 & 0,3 & 0,2 & 0,1 & 0,2 & 0,1 & 0,1 & 0,2 & 0,2 & 0,5 & 0,5 & \multicolumn{2}{|c|}{0,6} \\
\hline $\mathrm{Na}_{2} \mathrm{O}$ & 11,5 & 11,3 & 11,1 & 11,3 & 11,2 & 11,3 & 11,4 & 11,4 & 11,5 & 11,1 & 11,0 & \multicolumn{2}{|c|}{10,9} \\
\hline $\mathrm{K}_{2} \mathrm{O}$ & 0,1 & 0,1 & 0,1 & 0,1 & 0,1 & 0,1 & 0,1 & 0,1 & 0,1 & 0,1 & 0,1 & \multicolumn{2}{|c|}{0,1} \\
\hline Total & 98,5 & 97,9 & 97,3 & 97,3 & 97,2 & 97,2 & 98,0 & 97,6 & 97,7 & 97,0 & 96,7 & \multicolumn{2}{|c|}{96,6} \\
\hline APUF & & & & & & & & & & & & & \\
\hline$\overline{\mathrm{Si}}$ & 3,0 & 3,0 & 3,0 & 3,0 & 3,0 & 3,0 & 3,0 & 3,0 & 3,0 & 3,0 & 2,9 & \multicolumn{2}{|c|}{2,9} \\
\hline Al IV & 1,0 & 1,1 & 1,1 & 1,0 & 1,0 & 1,1 & 1,0 & 1,0 & 1,0 & 1,0 & 1,1 & \multicolumn{2}{|c|}{1,1} \\
\hline $\mathrm{Fe}_{2} \mathrm{O}_{3}$ & 0,0 & 0,0 & 0,0 & 0,0 & 0,0 & 0,0 & 0,0 & 0,0 & 0,0 & 0,0 & 0,0 & \multicolumn{2}{|c|}{0,0} \\
\hline $\mathrm{BaO}$ & 0,0 & 0,0 & 0,0 & 0,0 & 0,0 & 0,0 & 0,0 & 0,0 & 0,0 & 0,0 & 0,0 & \multicolumn{2}{|c|}{0,0} \\
\hline$\overline{\mathrm{CaO}}$ & 0,0 & 0,0 & 0,0 & 0,0 & 0,0 & 0,0 & 0,0 & 0,0 & 0,0 & 0,0 & 0,0 & \multicolumn{2}{|c|}{0,0} \\
\hline $\mathrm{Na}_{2} \mathrm{O}$ & 1,0 & 1,0 & 1,0 & 1,0 & 1,0 & 1,0 & 1,0 & 1,0 & 1,0 & 1,0 & 1,0 & \multicolumn{2}{|c|}{1,0} \\
\hline $\mathrm{K}_{2} \mathrm{O}$ & 0,0 & 0,0 & 0,0 & 0,0 & 0,0 & 0,0 & 0,0 & 0,0 & 0,0 & 0,0 & 0,0 & \multicolumn{2}{|c|}{0,0} \\
\hline Ab & 99,3 & 98,1 & 98,8 & 99,0 & 98,6 & 98,9 & 99,2 & 98,6 & 98,6 & 97,3 & 96,9 & \multicolumn{2}{|c|}{96,7} \\
\hline Anor & 0,2 & 1,5 & 0,8 & 0,5 & 0,9 & 0,7 & 0,4 & 0,9 & 1,0 & 2,3 & 2,6 & \multicolumn{2}{|c|}{2,9} \\
\hline Or & 0,5 & 0,4 & 0,4 & 0,5 & 0,5 & 0,4 & 0,4 & 0,5 & 0,4 & 0,4 & 0,5 & & 0,4 \\
\hline
\end{tabular}

São Paulo, UNESP, Geociências, v. 39, n. 3, p. 609 - 630, 2020 


\section{Mica}

\section{Micas Trioctaédricas}

Existem duas variedades principais de micas trioctaédricas no Granito Correas, as variedades pertencentes ao grupo da biotita e as variedades litiníferas. As micas pertencentes ao grupo da biotita ocorrem nas fácies biotita monzogranito porfirítico e biotita-muscovita sienogranito porfirítico. Foram analisados 14 cristais pertencentes ao grupo da biotita nas amostras CR-06 (fácies biotita monzogranito porfirítico) e CR-42 (fácies biotita-muscovita sienogranito porfirítico). Porém, na segunda amostra, as micas analisadas já estão quase completamente alteradas para clorita (pseudomorfos de biotita) $\mathrm{e}$, portanto, as amostras não puderam ser plotadas no diagrama de classificação de biotitas, e foram plotados no diagrama de classificação de cloritas.

O conteúdo de átomos por unidade de fórmula para os cristais de biotita analisados de cada amostra foi calculado na base de 22 oxigênios e estão apresentadas na tabela 2. De acordo com o diagrama $\mathrm{Al}(\mathrm{IV})$ versus $\mathrm{Fe}^{2+} /\left(\mathrm{Fe}^{2+}+\mathrm{Mg}\right.$ ) (Speer, 1984), os cristais de biotita analisados são quimicamente classificados entre a annita e siderofilita (Figura 5a, Tabela 2) e possuem conteúdo de $\mathrm{Mg}$ de 0,793 a 0,879 a.p.u.f, $\mathrm{Fe}^{2+}$ de 3,523 a 4,046 a.p.u.f, $\mathrm{Al}^{\mathrm{IV}}$ de 2,365 a 2,527 a.p.u.f, $\mathrm{Al}^{\mathrm{VI}}$ de 0,5 a 0,9 a.p.u.f. e Ti de 2,3 a 3,2 a.p.u.f.

De acordo com o diagrama de Hey (1954), os cristais de clorita analisados são quimicamente classificados como pseudoturingita (Figura 5b, Tabela 2) e possuem conteúdo de $\mathrm{Si}$ de 4,15 a 4,65 a.p.u.f., $\mathrm{Mg}$ de 0,786 a 0,933 a.p.u.f., $\mathrm{Fe}^{2+}$ de 5,190 a 5,977 a.p.u.f. e $\mathrm{Al}^{\mathrm{IV}}$ de 3,34 a 3,84 a.p.u.f. A mica litinífera (Figura 6 A) ocorre apenas nas variedades de coloração branca e cinza da fácies mica-albita granito porfirítico com topázio. Foram analisados 11 cristais de micas litiníferas nas amostras CR-17 e CR-27a. O conteúdo de átomos por unidade de fórmula para os cristais de micas litiníferas analisados de cada amostra foram calculados na base de 24 oxigênios (Tabela 3). De acordo com a classificação de Tischendorf et al. (2004) e Tischendorf et al. (2007), os cristais analisados são quimicamente classificados como zinnwaldita (Figura 6 A, Tabela 3), com exceção de duas análises que indicaram a presença de micas dioctaédricas (muscovita) na amostra CR17 do de $\mathrm{Fe}$ varia de 1,016 a 1 a.p.u.f., Mn varia de 0,059 a 0,233 a.p.u.f, Ti varia de 0,026 a 0,045 a.p.u.f, $\mathrm{Al}^{\mathrm{VI}}$ varia de 2,092 a 2,859 a.p.u.f, $\mathrm{Mg}$ varia de 0,031 a 0,041 a.p.u.f. e Li varia de 0,882 a 1,373 a.p.u.f.

Tabela 2 - Análises químicas representativas de biotita.

\begin{tabular}{|c|c|c|c|c|c|c|c|c|c|c|c|c|c|}
\hline \multirow[b]{2}{*}{ Amostra } & \multirow{2}{*}{ CR-06 } & \multirow{2}{*}{ CR-06 } & & & & & & & & & & & \\
\hline & & & CR-06 & CR-06 & CR-06 & CR-06 & CR-42 & CR-42 & CR-42 & CR-42 & CR-42 & CR-42 & CR-42 \\
\hline Cristal & 1 & 1 & 2 & 2 & 3 & 3 & 1 & 1 & 2 & 2 & 3 & 3 & 4 \\
\hline $\mathrm{SiO}_{2}$ & 32,8 & 34,3 & 34,2 & 34,4 & 33,9 & 34,3 & 24,9 & 25,5 & 22,6 & 23,2 & 23,0 & 25,7 & 22,4 \\
\hline $\mathrm{TiO}_{2}$ & 2,3 & 2,3 & 2,8 & 2,8 & 2,7 & 3,2 & 0,1 & 0,1 & 0,0 & 0,0 & 0,1 & 0,0 & 0,1 \\
\hline $\mathrm{Al}_{2} \mathrm{O}_{3}$ & 15,9 & 16,0 & 16,4 & 16,1 & 16,1 & 15,8 & 20,2 & 19,9 & 20,5 & 19,9 & 19,6 & 19,8 & 20,2 \\
\hline $\mathrm{FeO}$ & 29,0 & 26,7 & 25,8 & 26,3 & 26,0 & 26,3 & 36,3 & 35,1 & 38,9 & 39,1 & 38,5 & 34,3 & 38,5 \\
\hline MnO & 0,4 & 0,3 & 0,4 & 0,4 & 0,4 & 0,4 & 0,8 & 0,7 & 0,9 & 0,9 & 0,8 & 0,7 & 0,8 \\
\hline MgO & 3,3 & 3,4 & 3,6 & 3,6 & 3,2 & 3,4 & 3,4 & 3,4 & 3,2 & 3,3 & 2,8 & 3,2 & 3,4 \\
\hline $\mathrm{CaO}$ & 0,0 & 0,0 & 0,0 & 0,0 & 0,0 & 0,0 & 0,1 & 0,1 & 0,1 & 0,1 & 0,1 & 0,3 & 0,1 \\
\hline $\mathrm{Na}_{2} \mathrm{O}$ & 0,0 & 0,0 & 0,1 & 0,0 & 0,1 & 0,1 & 0,0 & 0,1 & 0,0 & 0,0 & 0,0 & 0,1 & 0,0 \\
\hline $\mathbf{K}_{2} \mathbf{O}$ & 7,9 & 9,0 & 9,1 & 9,1 & 8,7 & 8,7 & 0,5 & 0,7 & 0,1 & 0,1 & 0,4 & 0,9 & 0,1 \\
\hline $\mathrm{BaO}$ & 0,1 & 0,1 & 0,1 & 0,0 & 0,2 & 0,1 & 0,0 & 0,0 & 0,0 & 0,0 & 0,1 & 0,0 & 0,0 \\
\hline Total & 95,4 & 95,9 & 96,2 & 96,6 & 94,9 & 95,9 & 89,6 & 88,9 & 89,5 & 90,0 & 88,7 & 88,4 & 88,8 \\
\hline \multicolumn{14}{|l|}{ APUF } \\
\hline $\mathrm{Si}$ & 5,5 & 5,6 & 5,6 & 5,6 & 5,6 & 5,6 & 4,5 & 4,6 & 4,2 & 4,2 & 4,3 & 4,7 & 4,2 \\
\hline Al iv & 2,5 & 2,4 & 2,4 & 2,4 & 2,4 & 2,4 & 3,5 & 3,4 & 3,8 & 3,8 & 3,7 & 3,3 & 3,8 \\
\hline Al vi & 0,6 & 0,7 & 0,7 & 0,7 & 0,8 & 0,7 & 0,8 & 0,8 & 0,6 & 0,5 & 0,6 & 0,9 & 0,6 \\
\hline $\mathbf{T i}$ & 0,3 & 0,3 & 0,3 & 0,3 & 0,3 & 0,4 & 0,0 & 0,0 & 0,0 & 0,0 & 0,0 & 0,0 & 0,0 \\
\hline $\mathbf{F e}$ & 4,0 & 3,7 & 3,5 & 3,6 & 3,6 & 3,6 & 5,5 & 5,3 & 6,0 & 6,0 & 6,0 & 5,2 & 6,0 \\
\hline Mn & 0,1 & 0,0 & 0,1 & 0,1 & 0,1 & 0,1 & 0,1 & 0,1 & 0,1 & 0,1 & 0,1 & 0,1 & 0,1 \\
\hline $\mathrm{Mg}$ & 0,8 & 0,8 & 0,9 & 0,9 & 0,8 & 0,8 & 0,9 & 0,9 & 0,9 & 0,9 & 0,8 & 0,9 & 0,9 \\
\hline Ca & 0,0 & 0,0 & 0,0 & 0,0 & 0,0 & 0,0 & 0,0 & 0,0 & 0,0 & 0,0 & 0,0 & 0,1 & 0,0 \\
\hline $\mathbf{N a}$ & 0,0 & 0,0 & 0,0 & 0,0 & 0,0 & 0,0 & 0,0 & 0,0 & 0,0 & 0,0 & 0,0 & 0,0 & 0,0 \\
\hline $\mathbf{K}$ & 1,7 & 1,9 & 1,9 & 1,9 & 1,8 & 1,8 & 0,1 & 0,2 & 0,0 & 0,0 & 0,1 & 0,2 & 0,0 \\
\hline Ba & 0,0 & 0,0 & 0,0 & 0,0 & 0,0 & 0,0 & 0,0 & 0,0 & 0,0 & 0,0 & 0,0 & 0,0 & 0,0 \\
\hline $\mathrm{Fe} / \mathrm{Fe}+\mathrm{Mg}$ & 0,8 & 0,8 & 0,8 & 0,8 & 0,8 & 0,8 & 0,9 & 0,9 & 0,9 & 0,9 & 0,9 & 0,9 & 0,9 \\
\hline
\end{tabular}



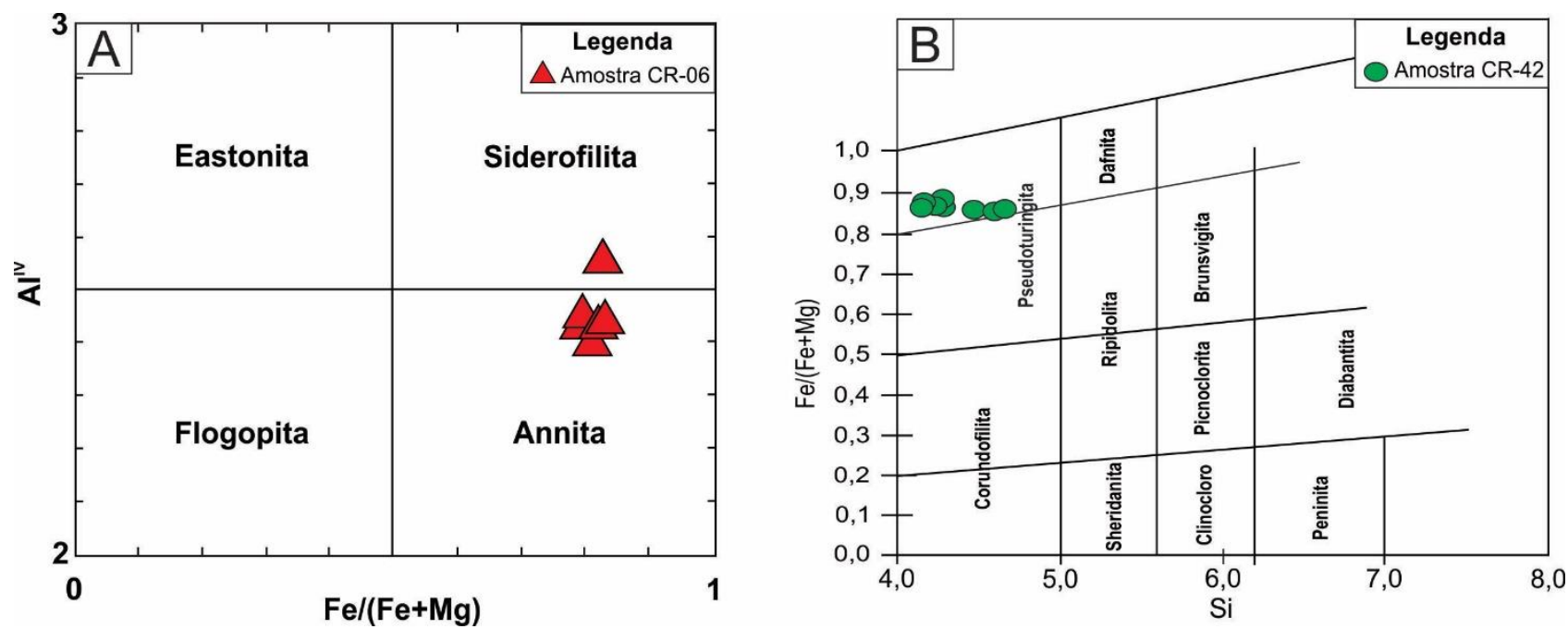

Figura 5 - A) Diagrama de classificação de biotita. CR-06: Amostra do biotita monzogranito porfirítico. B) Diagrama de classificação clorita (modificado de Hey, 1954). CR-42: Amostra do biotita-muscovita sienogranito porfirítico.

Tabela 3 - Análises químicas representativas de zinnwaldita. $\mathrm{LiO}_{2}$ calculado a partir de Monier \& Robert (1986a, b), $\mathrm{H}_{2} \mathrm{O}$ calculado a partir de Tindle \& Webb (1990).

\begin{tabular}{|c|c|c|c|c|c|c|c|c|c|c|c|}
\hline Amostra & CR-17 & CR-17 & CR-17 & CR-17 & CR-17 & CR-17 & CR-27a & CR-27a & CR-27a & CR-27a & CR-27a \\
\hline Cristal & 1 & 2 & 3 & 4 & 5 & 6 & 1 & 2 & 3 & 4 & 5 \\
\hline $\mathrm{SiO}_{2}$ & 40,82 & 41,35 & 43,74 & 44,13 & 40,33 & 41,70 & 40,91 & 41,19 & 41,59 & 41,35 & 41,73 \\
\hline $\mathrm{TiO}_{2}$ & 0,22 & 0,23 & 0,25 & 0,21 & 0,35 & 0,29 & 0,39 & 0,32 & 0,24 & 0,24 & 0,29 \\
\hline $\mathrm{Al}_{2} \mathrm{O}_{3}$ & 21,43 & 22,22 & 26,21 & 26,61 & 21,92 & 21,93 & 21,09 & 20,69 & 21,16 & 21,17 & 21,21 \\
\hline $\mathrm{FeO}$ & 14,12 & 13,10 & 8,71 & 8,45 & 15,08 & 13,85 & 13,85 & 13,52 & 13,29 & 13,33 & 12,54 \\
\hline $\mathrm{MnO}$ & 0,93 & 0,89 & 0,49 & 0,48 & 0,95 & 0,92 & 1,73 & 1,71 & 1,70 & 1,76 & 1,80 \\
\hline $\mathrm{MgO}$ & 0,17 & 0,17 & 0,15 & 0,15 & 0,18 & 0,17 & 0,17 & 0,14 & 0,15 & 0,17 & 0,14 \\
\hline $\mathrm{Na}_{2} \mathrm{O}$ & 0,15 & 0,14 & 0,07 & 0,08 & 0,09 & 0,09 & 0,08 & 0,15 & 0,16 & 0,16 & 0,14 \\
\hline $\mathrm{K}_{2} \mathrm{O}$ & 9,22 & 9,44 & 10,13 & 10,16 & 9,45 & 9,35 & 9,44 & 9,30 & 9,28 & 9,21 & 8,99 \\
\hline $\mathrm{BaO}$ & 0,03 & 0,03 & 0,01 & 0,02 & 0,00 & 0,02 & 0,00 & 0,01 & 0,02 & 0,04 & 0,06 \\
\hline $\mathbf{F}$ & 6,53 & 7,12 & 5,71 & 5,14 & 6,72 & 6,87 & 7,12 & 7,37 & 6,88 & 7,02 & 7,14 \\
\hline $\mathrm{Cl}$ & 0,00 & 0,01 & 0,00 & 0,00 & 0,01 & 0,00 & 0,00 & 0,00 & 0,00 & 0,00 & 0,01 \\
\hline $\mathbf{L i}_{2} \mathbf{O}^{*}$ & 1,96 & 2,14 & 1,70 & 1,52 & 2,02 & 2,06 & 2,14 & 2,22 & 2,07 & 2,11 & 2,15 \\
\hline $\mathrm{H}_{2} \mathrm{O} *$ & 0,79 & 0,57 & 1,44 & 1,73 & 0,73 & 0,71 & 0,53 & 0,40 & 0,66 & 0,59 & 0,53 \\
\hline Total & 93,63 & 94,42 & 96,19 & 96,53 & 94,99 & 95,05 & 94,45 & 93,94 & 94,29 & 94,19 & 93,70 \\
\hline \multicolumn{12}{|l|}{ APUF } \\
\hline $\mathbf{S i}$ & 6,29 & 6,28 & 6,33 & 6,35 & 6,17 & 6,31 & 6,28 & 6,34 & 6,36 & 6,33 & 6,38 \\
\hline Al IV & 1,71 & 1,72 & 1,67 & 1,65 & 1,83 & 1,69 & 1,72 & 1,66 & 1,64 & 1,67 & 1,62 \\
\hline Al vi & 2,19 & 2,26 & 2,80 & 2,86 & 2,12 & 2,22 & 2,09 & 2,09 & 2,17 & 2,15 & 2,21 \\
\hline $\mathbf{T i}$ & 0,03 & 0,03 & 0,03 & 0,02 & 0,04 & 0,03 & 0,05 & 0,04 & 0,03 & 0,03 & 0,03 \\
\hline $\mathbf{F e}$ & 1,82 & 1,66 & 1,05 & 1,02 & 1,93 & 1,75 & 1,78 & 1,74 & 1,70 & 1,71 & 1,60 \\
\hline Mn & 0,12 & 0,11 & 0,06 & 0,06 & 0,12 & 0,12 & 0,22 & 0,22 & 0,22 & 0,23 & 0,23 \\
\hline Mg & 0,04 & 0,04 & 0,03 & 0,03 & 0,04 & 0,04 & 0,04 & 0,03 & 0,03 & 0,04 & 0,03 \\
\hline $\mathbf{L i}^{*}$ & 1,21 & 1,31 & 0,99 & 0,88 & 1,24 & 1,26 & 1,32 & 1,37 & 1,27 & 1,30 & 1,32 \\
\hline $\mathrm{Na}$ & 0,04 & 0,04 & 0,02 & 0,02 & 0,03 & 0,03 & 0,02 & 0,05 & 0,05 & 0,05 & 0,04 \\
\hline $\mathbf{K}$ & 1,81 & 1,83 & 1,87 & 1,86 & 1,85 & 1,80 & 1,85 & 1,82 & 1,81 & 1,80 & 1,75 \\
\hline $\mathbf{B a}$ & 0,00 & 0,00 & 0,00 & 0,00 & 0,00 & 0,00 & 0,00 & 0,00 & 0,00 & 0,00 & 0,00 \\
\hline $\mathrm{OH}^{*}$ & 0,82 & 0,57 & 1,39 & 1,66 & 0,75 & 0,71 & 0,55 & 0,41 & 0,68 & 0,60 & 0,54 \\
\hline $\mathbf{F}$ & 3,18 & 3,42 & 2,61 & 2,34 & 3,25 & 3,29 & 3,45 & 3,59 & 3,32 & 3,40 & 3,46 \\
\hline $\mathrm{Cl}$ & 0,00 & 0,00 & 0,00 & 0,00 & 0,00 & 0,00 & 0,00 & 0,00 & 0,00 & 0,00 & 0,00 \\
\hline Mg-Li & $-1,17$ & $-1,27$ & $-0,96$ & $-0,85$ & $-1,20$ & $-1,22$ & $-1,28$ & $-1,34$ & $-1,24$ & $-1,26$ & $-1,29$ \\
\hline $\begin{array}{l}\text { Fe+Mn+ } \\
\text { Ti-AIVI }\end{array}$ & $-0,22$ & $-0,46$ & $-1,66$ & $-1,76$ & $-0,03$ & $-0,32$ & $-0,04$ & $-0,09$ & $-0,22$ & $-0,19$ & $-0,34$ \\
\hline
\end{tabular}

\section{Micas Dioctaédricas}

As micas dioctaédricas (Tabela 4) ocorrem na fácies biotita-muscovita sienogranito porfirítico (Amostra CR-42) e na variedade de coloração São Paulo, UNESP, Geociências, v. 39, n. 3, p. 609 - 630, 2020 
rosa da fácies mica-albita granito porfirítico com topázio (Amostra CR-28).

Também foram analisadas micas dioctaédricas secundárias na fácies biotita

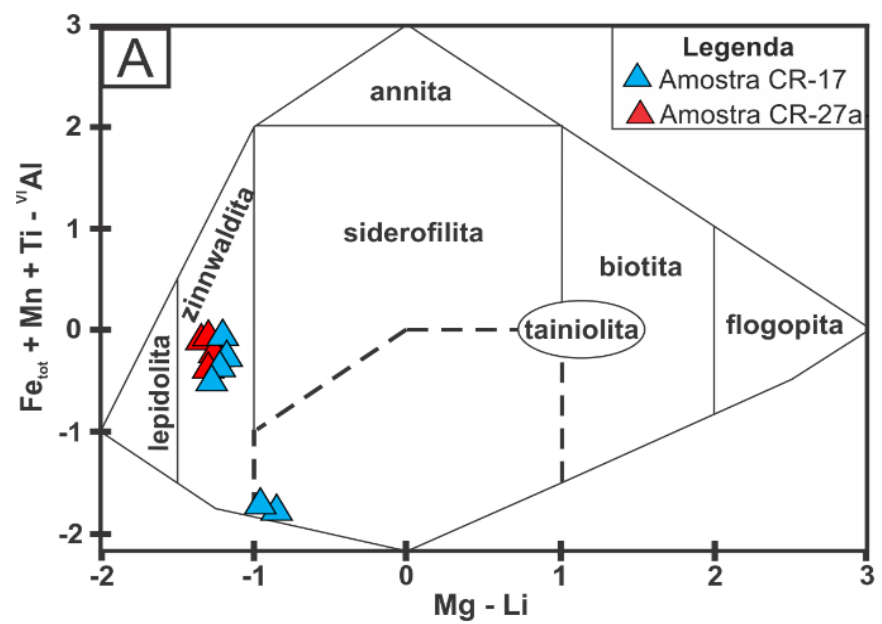

monzogranito porfirítico (Amostra CR-06) e na variedade sem micas primárias da fácies micaalbita granito porfirítico com topázio (Amostra CR-27b).

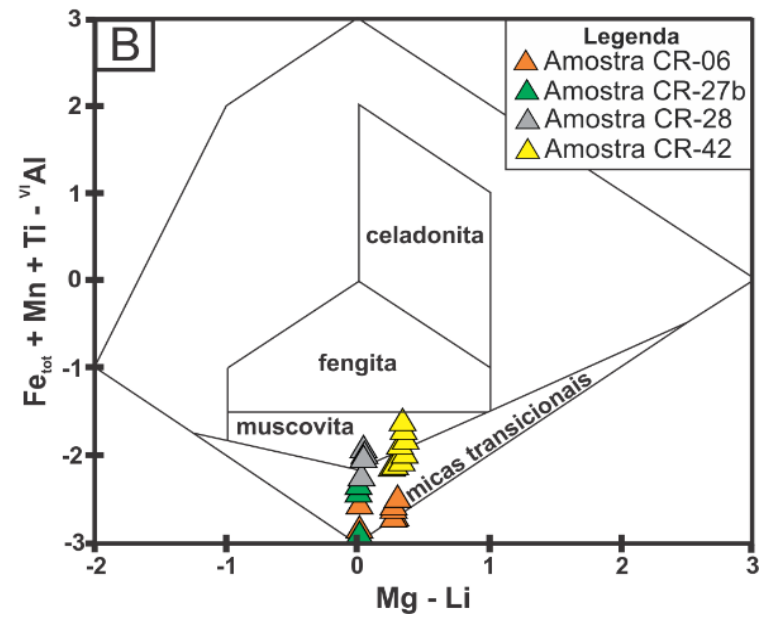

Figura 6 - Diagrama de classificação de micas. A) Tischendorf et al. (2004); B) Modificado de Tischendorf et al. (2004) e Tischendorf et al. (2007).

Tabela 4 - Análises químicas representativas de muscovita. $\mathrm{H}_{2} \mathrm{O}$ calculado a partir de Tindle \& Webb (1990).

\begin{tabular}{|c|c|c|c|c|c|c|c|c|c|c|c|c|c|c|}
\hline Amostra & CR-28 & CR-28 & CR-28 & CR-28 & CR-28 & CR-28 & CR-06 & CR-06 & CR-06 & CR-06 & CR-06 & CR-06 & CR-42 & CR-42 \\
\hline Cristal & 1 & 1 & 2 & 2 & 3 & 3 & 1 & 1 & 2 & 2 & 3 & 3 & 1 & 1 \\
\hline $\mathrm{SiO}_{2}$ & 45,11 & 44,96 & 43,84 & 43,82 & 43,98 & 43,18 & 44,38 & 44,08 & 44,97 & 45,01 & 44,24 & 43,75 & 43,59 & 44,72 \\
\hline TiO2 & 0,00 & 0,00 & 0,23 & 0,32 & 0,10 & 0,23 & 0,17 & 0,20 & 0,25 & 0,23 & 0,24 & 0,22 & 0,67 & 0,65 \\
\hline $\mathrm{Al}_{2} \mathrm{O}_{3}$ & 30,41 & 28,97 & 27,65 & 28,01 & 28,77 & 27,71 & 29,47 & 29,35 & 29,71 & 29,60 & 28,98 & 29,88 & 26,94 & 27,69 \\
\hline $\mathrm{FeO}$ & 4,86 & 6,49 & 8,89 & 8,64 & 7,96 & 8,59 & 5,61 & 6,02 & 4,90 & 4,95 & 5,44 & 5,61 & 8,07 & 7,33 \\
\hline $\mathrm{MnO}$ & 0,30 & 0,29 & 0,43 & 0,40 & 0,34 & 0,26 & 0,10 & 0,12 & 0,08 & 0,08 & 0,07 & 0,06 & 0,26 & 0,19 \\
\hline MgO & 0,04 & 0,05 & 0,19 & 0,18 & 0,12 & 0,18 & 1,30 & 1,40 & 1,33 & 1,25 & 1,26 & 1,23 & 1,46 & 1,53 \\
\hline $\mathrm{CaO}$ & 0,00 & 0,00 & 0,00 & 0,00 & 0,00 & 0,00 & 0,00 & 0,00 & 0,00 & 0,00 & 0,00 & 0,00 & 0,00 & 0,00 \\
\hline $\mathrm{Na}_{2} \mathrm{O}$ & 0,10 & 0,11 & 0,20 & 0,22 & 0,18 & 0,14 & 0,18 & 0,18 & 0,28 & 0,31 & 0,18 & 0,15 & 0,33 & 0,31 \\
\hline $\mathrm{K}_{2} \mathrm{O}$ & 9,64 & 9,75 & 10,06 & 9,95 & 10,06 & 10,22 & 10,27 & 10,24 & 9,91 & 9,86 & 10,25 & 10,14 & 9,99 & 9,93 \\
\hline $\mathrm{BaO}$ & 0,00 & 0,01 & 0,00 & 0,06 & 0,00 & 0,05 & 0,13 & 0,13 & 0,13 & 0,16 & 0,02 & 0,01 & 0,02 & 0,02 \\
\hline $\mathrm{Cl}$ & 0,00 & 0,00 & 0,01 & 0,02 & 0,01 & 0,01 & 0,01 & 0,01 & 0,00 & 0,01 & 0,01 & 0,02 & 0,01 & 0,01 \\
\hline H2O* & 4,21 & 4,18 & 4,13 & 4,14 & 4,16 & 4,09 & 4,21 & 4,20 & 4,24 & 4,23 & 4,18 & 4,19 & 4,13 & 4,21 \\
\hline Total & 94,68 & 94,82 & 95,63 & 95,75 & 95,68 & 94,67 & 95,83 & 95,93 & 95,81 & 95,69 & 94,86 & 95,26 & 95,47 & \begin{tabular}{|c|}
96,59 \\
\end{tabular} \\
\hline \multicolumn{15}{|l|}{ APUF } \\
\hline $\mathbf{S i}$ & 6,42 & 6,46 & 6,36 & 6,34 & 6,34 & 6,33 & 6,32 & 6,28 & 6,36 & 6,37 & 6,35 & 6,26 & 6,32 & 6,36 \\
\hline Al IV & 1,58 & 1,54 & 1,64 & 1,66 & 1,66 & 1,67 & 1,68 & 1,72 & 1,64 & 1,63 & 1,65 & 1,74 & 1,68 & 1,64 \\
\hline Al VI & 3,52 & 3,36 & 3,09 & 3,12 & 3,22 & 3,12 & 3,26 & 3,22 & 3,31 & 3,31 & 3,25 & 3,29 & 2,93 & 3,01 \\
\hline $\mathbf{T i}$ & 0,00 & 0,00 & 0,03 & 0,03 & 0,01 & 0,03 & 0,02 & 0,02 & 0,03 & 0,02 & 0,03 & 0,02 & 0,07 & 0,07 \\
\hline $\mathrm{Fe}$ & 0,58 & 0,78 & 1,08 & 1,05 & 0,96 & 1,05 & 0,67 & 0,72 & 0,58 & 0,59 & 0,65 & 0,67 & 0,98 & 0,87 \\
\hline Mn & 0,04 & 0,04 & 0,05 & 0,05 & 0,04 & 0,03 & 0,01 & 0,01 & 0,01 & 0,01 & 0,01 & 0,01 & 0,03 & 0,02 \\
\hline $\mathrm{Mg}$ & 0,01 & 0,01 & 0,04 & 0,04 & 0,03 & 0,04 & 0,28 & 0,30 & 0,28 & 0,26 & 0,27 & 0,26 & 0,32 & 0,32 \\
\hline $\mathbf{N a}$ & 0,03 & 0,03 & 0,06 & 0,06 & 0,05 & 0,04 & 0,05 & 0,05 & 0,08 & 0,08 & 0,05 & 0,04 & 0,09 & 0,09 \\
\hline K & 1,75 & 1,79 & 1,86 & 1,84 & 1,85 & 1,91 & 1,86 & 1,86 & 1,79 & 1,78 & 1,88 & 1,85 & 1,85 & 1,80 \\
\hline Ba & 0,00 & 0,00 & 0,00 & 0,00 & 0,00 & 0,00 & 0,01 & 0,01 & 0,01 & 0,01 & 0,00 & 0,00 & 0,00 & 0,00 \\
\hline OH* & 4,00 & 4,00 & 4,00 & 4,00 & 4,00 & 4,00 & 4,00 & 4,00 & 4,00 & 4,00 & 4,00 & 4,00 & 4,00 & 4,00 \\
\hline $\mathrm{Cl}$ & 0,00 & 0,00 & 0,00 & 0,00 & 0,00 & 0,00 & 0,00 & 0,00 & 0,00 & 0,00 & 0,00 & 0,00 & 0,00 & 0,00 \\
\hline $\mathrm{Fe} / \mathrm{Fe}+\mathrm{Mg}$ & 0,98 & 0,99 & 0,96 & 0,96 & 0,97 & 0,96 & 0,71 & 0,71 & 0,67 & 0,69 & 0,71 & 0,72 & 0,76 & 0,73 \\
\hline Mg-Li & 0,01 & 0,01 & 0,04 & 0,04 & 0,03 & 0,04 & 0,28 & 0,30 & 0,28 & 0,26 & 0,27 & 0,26 & 0,32 & 0,32 \\
\hline $\begin{array}{l}\text { Fe+Mn+Ti- } \\
\text { AlVI }\end{array}$ & $-2,90$ & $-2,54$ & 94 & $-1,99$ & $-2,21$ & $-2,01$ & $-2,56$ & $-2,46$ & $-2,69$ & $-2,69$ & $-2,56$ & $-2,59$ & $-1,84$ & $-2,04$ \\
\hline
\end{tabular}

No total foram analisados 28 cristais de micas tabela 4. O conteúdo de átomos por unidade de dioctaédricas nas amostras mencionadas na fórmula para os cristais de muscovita analisados 
de cada amostra foram calculados na base de 24 oxigênios e estão representados na tabela 4. De acordo com a classificação de Tischendorf et al. (2004) e Tischendorf et al. (2007), os cristais de mica primária analisados são quimicamente classificados como muscovita e os cristais de mica secundária são classificados como micas transicionais (Figura 6 B, Tabela 4). O conteúdo de Fe varia de 0,57 a 1,14 a.p.u.f., Mn varia de 0,01 a 0,10 a.p.u.f., Ti varia de 0,0 a 0,08 a.p.u.f., $\mathrm{Al}^{\mathrm{VI}}$ varia de 2,82 a 3,52 a.p.u.f., $\mathrm{Mg}$ varia de 0,0 a 0,36 a.p.u.f. e $\mathrm{Li}>0,02$ a.p.u.f. No geral os cristais de muscovita primária possuem maiores quantidades de $\mathrm{FeO}, \mathrm{TiO}_{2}$ e $\mathrm{Mno}$, e menores quantidades de $\mathrm{Al}_{2} \mathrm{O}_{3}$ em relação as muscovitas secundárias. Dentro da mesma associação de fácies (mica-albita granito) são encontradas duas variedades de micas, a zinnwaldita e a muscovita, nas fácies onde a zinnwaldita é encontrada é possível observar que a mica presente possui maior quantidade de $\mathrm{TiO}_{2}, \mathrm{FeO}, \mathrm{MnO}$ e menor quantidade de $\mathrm{Al}_{2} \mathrm{O}_{3}$ e $\mathrm{MgO}$ em relação as fácies onde a muscovita está presente, além da presença de $\mathrm{Li}_{2} \mathrm{O}$ na variedade litinífera. Segundo Muller \& Seltmann, (1999), a presença da zinnwaldita em conjunto com a albita na fase final sugere que o magma era supersaturado em fluídos e enriquecido em F-Li.

Tabela 4 (continuação) - Análises químicas representativas de muscovita (continuação). $\mathrm{H}_{2} \mathrm{O}$ calculado a partir de Tindle \& Webb (1990).

\begin{tabular}{|c|c|c|c|c|c|c|c|c|c|c|c|c|c|c|}
\hline & & & & & & & & & & & & & & \\
\hline Amostra & 42 & 42 & 42 & 42 & 42 & 42 & 42 & 42 & 42 & 42 & $27 b$ & $27 \mathrm{~b}$ & $27 b$ & $27 b$ \\
\hline Cristal & 2 & 2 & 3 & 3 & 4 & . & 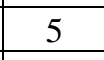 & 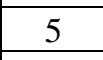 & 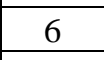 & 6 & 1 & 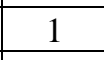 & 2 & 2 \\
\hline 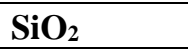 & 3,18 & 3,41 & 3,71 & 44,07 & 43,59 & 4,05 & 4,33 & 3,69 & 43,22 & 4,12 & 5,34 & 4,86 & 5,81 & \\
\hline & & 52 & 70 & 42 & 0,67 & 64 & 34 &, 33 &, 61 &, 55 &, 00 &, 00 &, 01 &, 01 \\
\hline & 86 & 33 & 23 &, 01 & 26,75 &, 79 & 80 & 27,75 & 26,09 & 28 & 7,94 & 27,94 & 28,07 & 0,86 \\
\hline & & & 62 & & 07 & 27 & 46 &, 42 & & & 97 & 35 & & \\
\hline & & & & & & & & 22 & & & & & & \\
\hline & & 1,57 & & & & & 1,24 & 25 & & & & 01 & & \\
\hline & & 0,00 & & & & & 0,00 & & & & & 00 & & \\
\hline & & 0.43 & & & & & 027 & & & & & 11 & & \\
\hline & & 97 & 9.4 & & 9,73 & & 07 & & & &, 02 & 16 & & \\
\hline & & & 0.0 & & 000 & 0.0 & 0 & & & & & & & \\
\hline $\bar{C}$ & & 0 & & & & 0 . & 0 & & & & & & & \\
\hline & & & 4,13 & 4,14 & 4,12 & 4 & 418 & 4,14 & & & & & & 4,28 \\
\hline & & 06 & 1 & 95 & 95,00 & - & 9. & 95,12 & 9 & 06 & 34 & 0 & 96,32 & \\
\hline & & & & & & & & & & & & & & \\
\hline$\underline{S}$ & & & & & & & & & & & & & & \\
\hline & & & & & & & & & & & & & & \\
\hline & & & & & & & & & & & & & & \\
\hline $\mathbf{T i}$ & & & & & & & + & & & & & 0 & & \\
\hline $\mathbf{F}$ & & & & & & & 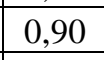 & 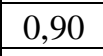 & & & & 9 & & \\
\hline & & 0,0 & & & 0,03 & & 0,0 & 0,0 & & & & 3 & & 01 \\
\hline M & & & & & & & & & & & & & & 01 \\
\hline $\mathrm{Na}$ & & 0,12 & & & & & O & 0,10 & & & 02 & 03 & 3 & 0,02 \\
\hline $\mathbf{K}$ & & 1,80 & & & & 1,70 & 1,79 & 1,83 & & & 84 & ,87 & & 86 \\
\hline Ba & & 0,00 & 0,0 & & & 0,00 & 0,00 & 0,00 & & 0,00 & 00 &, 00 & 0 & 0,00 \\
\hline OH & & 40 & & & & & 4,00 & 4,00 & & & 00 & 00 & & 4,00 \\
\hline Cl & & 0,0 & 0,0 & & 0 & 0, & 0,0 & 0,00 & 0,00 & 0,00 & 00 &, 00 & 0 & 0,00 \\
\hline & & 07 & & & & & 0,7 & 27 & & & 0 & 1,00 & 1,00 & 0,97 \\
\hline & & & & & & 0,2 & 40 & 0,27 & 0,33 & 0,34 & 4 & 00 &, 00 & 0,01 \\
\hline$e+1$ & 9 & 6 & ,97 & -1 & $-1,85$ & $-2,09$ & $-2,11$ & $-2,10$ & $|-1,58|$ & $\mid-1$ & $-2,40$ & $-2,33$ & $\mid-2,31$ & 92 \\
\hline
\end{tabular}

\section{LITOGEOQUÍMICA}

As análises geoquímicas realizadas nas rochas do Granito Correas são apresentadas na tabela 5. Os artigos de cunho geoquímico das rochas do Granito Correas são descritos nos trabalhos iniciais de Gimenez Filho (1993), Gimenez Filho et al. (1995) e Goraieb (1995).

A distribuição dos elementos maiores foi caracterizada nos diagramas de Harker (1909) (Figuras 7A a 7H), com teores elevados de sílica e distribuídos num intervalo restrito entre $72 \%$ a 
77\%. Os demais óxidos $\left(\mathrm{TiO}_{2}, \mathrm{FeOt}, \mathrm{MgO}\right.$ e $\mathrm{CaO}$ ) mostram correlação negativa em relação ao aumento em $\mathrm{SiO}_{2}$, evidenciando um empobrecimento em relação as rochas mais enriquecidas e indicam similaridade com as características de rochas holo- a leucocráticas, com acentuado empobrecimento em minerais máficos.

Tabela 5 - Resultado de análises geoquímicas de amostras das rochas do Granito Correas.

\begin{tabular}{|c|c|c|c|c|c|c|c|c|c|}
\hline \multirow{2}{*}{$\begin{array}{c}\text { Fácies } \\
\text { Amostra } \\
\end{array}$} & \multicolumn{3}{|c|}{ biotita monzogranito } & \multirow{2}{*}{\begin{tabular}{|c|}
$\begin{array}{l}\text { biotita-muscovita } \\
\text { sienogranito }\end{array}$ \\
CR-33 \\
\end{tabular}} & \multicolumn{4}{|c|}{ mica-albita granito } & \multirow{2}{*}{\begin{tabular}{|c|} 
pegmatito $\Lambda$ \\
CR-20 \\
\end{tabular}} \\
\hline & CR-4 & CR-5 & CR-6 & & CR-17 & CR-28 & CR-27A & CR-27B & \\
\hline $\mathrm{SiO}_{2}$ & 74,26 & 74,53 & 73,94 & 75,63 & 73,19 & 76,09 & 72,78 & 74,57 & 76,06 \\
\hline $\mathrm{TiO}_{2}$ & 0,15 & 0,14 & 0,19 & 0,07 & 0,02 & 0 & 0,01 & 0 & 0,01 \\
\hline $\mathrm{Al}_{2} \mathrm{O}_{3}$ & 12,99 & 13,04 & 12,95 & 12,96 & 14,67 & 14,39 & 16,07 & 14,91 & 14,82 \\
\hline $\mathrm{Fe}_{2} \mathrm{O}_{3}$ & 1,42 & 1,55 & 1,71 & 1,05 & 0,64 & 0,24 & 0,52 & 0,13 & 0,62 \\
\hline MnO & 0,04 & 0,04 & 0,04 & 0,01 & 0,03 & 0,01 & 0,06 & 0 & 0,07 \\
\hline MgO & 0,14 & 0,07 & 0,1 & 0 & 0 & 0 & 0 & 0 & 0 \\
\hline $\mathrm{CaO}$ & 0,61 & \begin{tabular}{|l|}
0,91 \\
\end{tabular} & 0,73 & 0,78 & 0,42 & 0,24 & 0,04 & 0,28 & 0,06 \\
\hline $\mathrm{Na}_{2} \mathrm{O}$ & 3,5 & 3,23 & 3,2 & 3,84 & 6,29 & 5,19 & 4,3 & 5,23 & 5,04 \\
\hline $\mathrm{K}_{2} \mathrm{O}$ & 5,4 & 5,45 & 5,33 & 4,65 & 3,59 & 4,11 & 4,37 & 5,02 & 3,1 \\
\hline $\mathrm{P}_{2} \mathrm{O}_{5}$ & 0,03 & 0,04 & 0,07 & 0,04 & 0,02 & 0,03 & 0,04 & 0,03 & 0,02 \\
\hline LOI & 0,83 & \begin{tabular}{|l|}
0,82 \\
\end{tabular} & 0,78 & 0,86 & 0,46 & 0,41 & 1,46 & 0,26 & 0,47 \\
\hline Total & 99,38 & 99,81 & 99,04 & 99,88 & 99,33 & 100,71 & 99,65 & 100,42 & 100,26 \\
\hline $\mathrm{Cr}$ & 27 & 36 & 32 & 25 & 20 & 14 & 12 & 18 & 11 \\
\hline $\mathrm{Cu}$ & 5 & 4 & 4 & 8 & $<3$ & $<3$ & $<3$ & $<3$ & $<3$ \\
\hline $\mathbf{N i}$ & $<3$ & 3 & 3 & $<3$ & $<3$ & $<3$ & $<3$ & $<3$ & $<3$ \\
\hline $\mathbf{Z n}$ & 22 & 28 & 33 & 16 & 7 & 8 & 12 & 7 & 19 \\
\hline Ba & 299 & 280 & 345 & 60 & $<3$ & 17 & 4 & 6 & 3 \\
\hline $\mathbf{R b}$ & 570 & 580 & 550 & 920 & 1120 & 1250 & 1130 & 1220 & 920 \\
\hline $\mathbf{G a}$ & 25 & 21 & 18 & 28 & 42 & 37 & 40 & 38 & 27 \\
\hline $\mathbf{S r}$ & 97 & 86 & 88 & 24 & 7 & 17 & 5 & 8 & 6 \\
\hline $\mathbf{Z r}$ & 126 & 128 & 155 & 84 & 31 & 23 & 30 & 24 & 21 \\
\hline $\mathbf{Y}$ & 313 & 63 & 84 & 101 & 24 & 8 & 5 & 11 & $<3$ \\
\hline Nb & 10 & 12 & 10 & 12 & 30 & 12 & 22 & 23 & 23 \\
\hline $\mathbf{L i}$ & 16 & 65 & 55 & 81 & 210 & 6 & 386 & 7 & 374 \\
\hline $\mathbf{U}$ & 14,94 & 12,74 & 12,07 & 11,45 & 13,38 & 10,86 & 4,77 & 10,03 & 2,53 \\
\hline Th & 50,5 & 45,2 & 46,6 & 32 & 15,3 & 13,5 & 10,6 & 13,4 & 8,4 \\
\hline $\mathbf{L a}$ & 561,5 & 50 & 174,6 & 42,3 & 20,5 & 16,7 & 38,9 & 58,4 & 6,4 \\
\hline $\mathrm{Ce}$ & 98,1 & \begin{tabular}{|l|}
87,9 \\
\end{tabular} & 147,3 & 49,7 & 51,4 & 38,1 & 20,3 & 52,1 & 15 \\
\hline Nd & 272,8 & 29,6 & 111,3 & 22,8 & 21,2 & 14 & 31,1 & 48 & 4,2 \\
\hline Sm & 55,7 & 6,1 & 20,8 & 7,3 & 8,7 & 4,6 & 7,7 & 13 & 1,1 \\
\hline $\mathbf{E u}$ & 6,12 & 0,61 & 2,22 & 0,46 & 0,05 & 0,06 & 0,31 & 0,7 & 0,05 \\
\hline Gd & 66,23 & 6,48 & 21,03 & 12,16 & 8,47 & 4,39 & 4,76 & 10,44 & 0,74 \\
\hline Dy & 60,4 & 8,13 & 18,2 & 21,57 & 14,21 & 8,48 & 5,76 & 14,21 & 1,42 \\
\hline $\mathbf{E r}$ & 28,94 & 7,36 & 9,42 & 15,18 & 10,26 & 6,46 & 3,8 & 9,1 & 1,06 \\
\hline $\mathbf{Y b}$ & 24,3 & 9,7 & 9,1 & 16,8 & 16,2 & 12 & 6,2 & 14,1 & 2 \\
\hline $\mathbf{L u}$ & 3,29 & \begin{tabular}{|l|}
1,57 \\
\end{tabular} & 1,31 & 2,37 & 2,4 & 1,78 & 0,87 & 2,09 & 0,28 \\
\hline$(\mathbf{L a} / \mathbf{Y b})_{\mathbf{n}}$ & 15,579 & 3,475 & 12,936 & 1,698 & 0,853 & 0,938 & 4,230 & 2,792 & 2,157 \\
\hline Média & \multicolumn{3}{|c|}{10,66} & 1,698 & \multicolumn{4}{|c|}{2,20} & 2,157 \\
\hline Eu* & 413,50 & 43,79 & 147,27 & 60,91 & 60,97 & 32,06 & 48,68 & 86,82 & 7,07 \\
\hline Média & \multicolumn{3}{|c|}{201,51} & 60,91 & \multicolumn{4}{|c|}{57,13} & 7,07 \\
\hline $\mathbf{E u} / \mathbf{E} \mathbf{u}^{*}$ & 0,20 & 0,19 & 0,21 & 0,10 & 0,01 & 0,03 & 0,09 & 0,11 & 0,10 \\
\hline Média & \multicolumn{3}{|c|}{0,20} & 0,10 & \multicolumn{4}{|c|}{0,06} & 0,10 \\
\hline Ce-Sm & 0,43 & 3,48 & 1,71 & 1,64 & 1,43 & 2,00 & 0,64 & 0,97 & 3,29 \\
\hline Média & \multicolumn{3}{|c|}{1,87} & 1,64 & \multicolumn{4}{|c|}{1,26} & 3,29 \\
\hline Gd-Yb & 2,20 & \begin{tabular}{|l|}
0,54 \\
\end{tabular} & 1,86 & 0,58 & 0,42 & 0,30 & 0,62 & 0,60 & 0,30 \\
\hline Média & \multicolumn{3}{|c|}{1,53} & 0,58 & \multicolumn{4}{|c|}{0,48} & 0,30 \\
\hline
\end{tabular}

Em relação a distribuição dos álcalis, os teores de $\mathrm{Na}_{2} \mathrm{O}$ são maiores na fácies mica-albita granito, chegando a mais de $6 \%$, enquanto os valores de $\mathrm{K}_{2} \mathrm{O}$ são maiores na fácies biotita monzogranito.

Valores estes que são condizentes com as rochas graníticas altamente diferenciadas, na qual há redução de feldspato potássico e aumento 
de plagioclásio sódico (albita).

As rochas graníticas podem ser agrupadas em duas fases magmáticas principais, a primeira dominante constituída por sienogranitos e monzogranitos porfiríticos, apresentando teores entre 74 e $76 \%$ de $\mathrm{SiO}_{2}$, e a segunda constituída por álcali-feldspato granitos porfiríticos, apresentando teores entre 72 e $77 \%$ de $\mathrm{SiO}_{2}$.

Também é possível observar um zoneamento de sul para norte do corpo com redução da granulação das rochas da fácies em direção aos termos mais diferenciados.

Após a fase magmática final, a constituição do

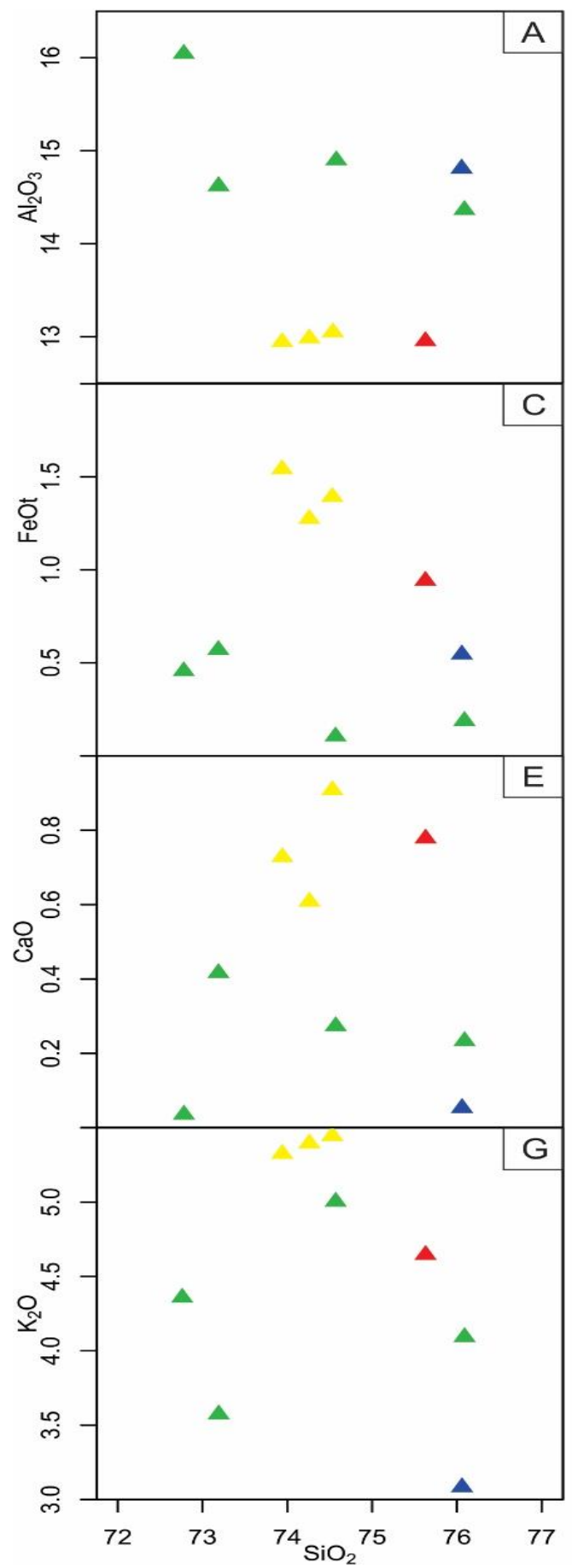

corpo granítico é caracterizada por intrusões localizadas constituídas por aplitos e pegmatitos mais diferenciados que vão afetar as demais fácies anteriores, sugerindo, portanto, que o magmatismo se desenvolveu por diferentes pulsos magmáticos que foram se diferenciando.

No diagrama modal QAP de Lameyre \& Bowden (1982), da figura 8B, as rochas ácidas são predominantemente classificadas como sienogranitos e álcali (albita) granitos de afinidade com as séries magmáticas cálcioalcalina monzogranítica de alto potássio a alcalina sódica.

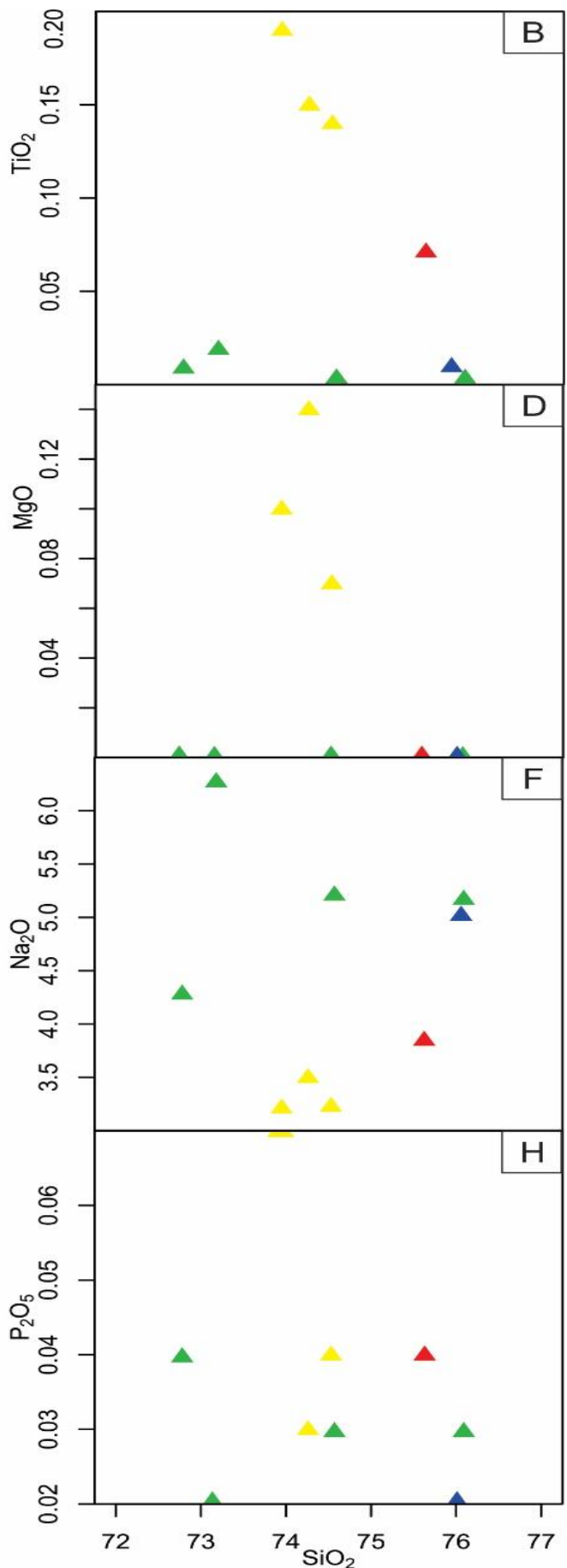

Figura 7 - Diagramas geoquímicos de variação para elementos maiores tipo Harker (1909) das amostras de rochas do Granito Correas. 

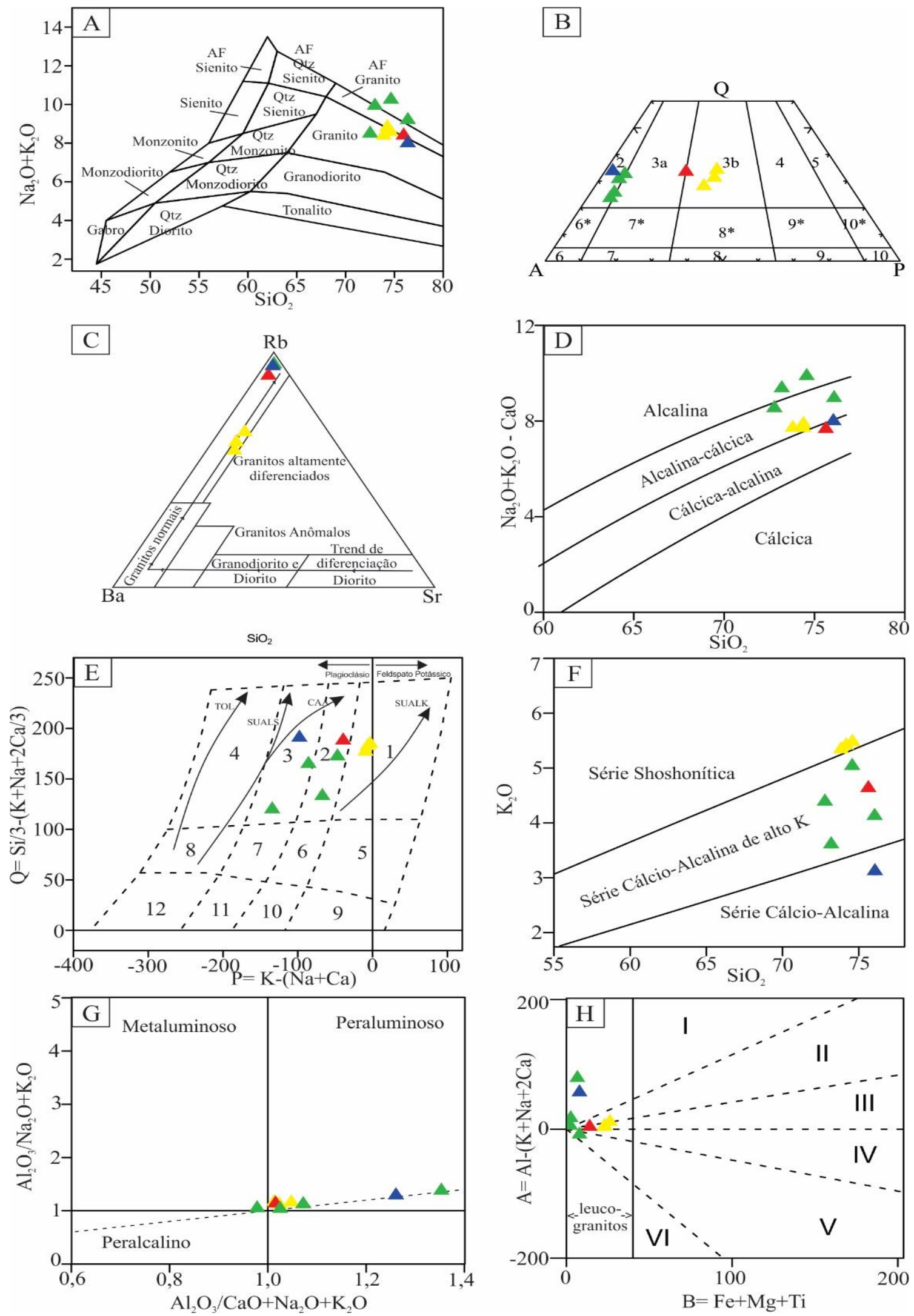

Figura 8 - Diagramas geoquímicos de classificação das amostras de rochas do Granito Correas. A) Middlemost (1985); B) Lameyre \& Bowden (1982) (2-álcali granito, 3a-sienogranitos, 3b-monzoganitos); C) El Bouseily \& El Sokkary (1975); D) Frost et al. (2001); E) Q x P de (Debon et al., 1988) Abr.: TOL=toleítica, CAA=cálcico-alcalina, SUBALS= subalcalina sódica, SUBALK= subalcalina potássica; F) Taylor (1976); G) Índice de Shand de Maniar \& Picolli (1989); H) Debon \& Le Fort (1983): leucogranito peraluminoso: campo I - muscovita > biotita; campo II - biotita > muscovita campo III- biotita; campo IV - biotita + hornblenda.

No diagrama petrográfico de Middlemost principalmente em dois campos petrográficos: os (1985), da figura 8A, as amostras distribuem-se das rochas ácidas definidos por granitos 
enriquecidos em sílica e álcalis, e o campo do o álcali (albita) granito.

Com base no diagrama ternário de El Bouseily \& El Sokkary (1975), da figura 8C, as rochas do Granito Correas são classificadas como granitos normais diferenciando-se para granitos altamente diferenciados.

$\mathrm{O}$ diagrama de séries magmáticas da figura 8D (Frost et al., 2001), define uma tendência de diferenciação com rochas iniciais cálcioalcalinas a alcalina-cálcicas e apresentando para rochas finais, mais diferenciadas, a tendência para série alcalina sódica.

O diagrama de classificação petrográfica que utiliza os parâmetros multicatiônicos $\mathrm{Q} v s \mathrm{P}$, de Debon et al. (1988) (Figura 8E), mostra que os litotipos são classificados como granitos de caráter cálcio-alcalino a alcalino.

No diagrama de classificação com relação ao teor em potássio de Taylor (1976) (Figura 8F), o maior número de amostras está distribuído no campo da série cálcio-alcalina de alto potássio, mas também se observa amostras com valores de $\mathrm{K}_{2} \mathrm{O}>5 \%$, de afinidade shoshonítica.

Quanto à saturação em alumínio, observa-se no diagrama de Shand (1943) (Figura 8G), que os litotipos apresentam caráter dominantemente peraluminoso. O diagrama de Debon \& Le Fort (1983) (Figura 8H) define para a sequência magmática a predominância de leucogranitos peraluminosos a muscovita > biotita (campo I) e leucogranitos peraluminosos a biotita (campo III).

Quanto à distribuição dos elementos traços nos diagramas binários das figuras $9 \mathrm{~A}$ a $9 \mathrm{~F}$, observa-se que a concentração de rubídio $(\mathrm{Rb})$ é alta, nos diagramas $\mathrm{Rb}$ vs $\mathrm{SiO}_{2}$ (Figura 9A) e $\mathrm{Rb}$ vs $\mathrm{K}_{2} \mathrm{O}$ (Figura 9B), no geral o rubídio está associado ao potássio do feldspato potássico e da biotita e possui uma leve correlação negativa com o incremento da sílica para os conjuntos analisados. Sugere-se que o decaimento de $\mathrm{Rb}$ se deve a associação com a diminuição na porcentagem de biotita para as rochas mais diferenciadas, já que a presença de feldspato potássico é elevada e constante nas amostras.

Em relação ao estrôncio ( $\mathrm{Sr}$ ), os litotipos mostram baixos valores e nos diagramas $\mathrm{Sr}$ vs $\mathrm{SiO}_{2}$ (Figura 9C) e $\mathrm{Sr} v s \mathrm{CaO}$ (Figura 9D) mostram uma leve correlação positiva dos agrupamentos de amostras com a sílica em associação direta na redução de plagioclásios para as rochas mais diferenciadas.
Portanto, sugere-se um processo de fracionamento magmático, com consequente aumento de plagioclásio sódico (albita) e feldspato potássico a partir da segregação e redução em plagioclásios cálcicos, e consequente empobrecimento de $\mathrm{Sr}$ do líquido magmático, disponível para as fases mais diferenciadas.

As quantidades de bário, no diagrama $\mathrm{Ba} v s$ $\mathrm{SiO}_{2}$ (Figura 9E) e $\mathrm{Ba} v s \mathrm{CaO}$ (Figura 9F) mostram baixos valores e é admitida sua associação com os plagioclásios cálcicos.

É possível observar uma diminuição da quantidade de $\mathrm{Ba}$ nas fácies mais diferenciadas devido à redução de plagioclásios cálcicos nessas rochas.

Os valores de zircônio no diagrama $\mathrm{Zr} v s \mathrm{SiO}_{2}$ (Figura 9G) mostra correlação negativa para as fácies mais diferenciadas.

$\mathrm{O}$ decréscimo do $\mathrm{Zr}$ indica forte fracionamento ao longo da evolução dos líquidos e sua diminuição nas concentrações nos líquidos mais diferenciados finais, sugere $o$ fracionamento de titanomagnetita, ilmenita e zircão no processo evolutivo do líquido magmático.

Os valores de $\mathrm{Nb}$ (Figura 9H) são elevados e não definem uma tendência, apresentando a disposição das amostras horizontalizada a leve correlação negativa com $\mathrm{SiO}_{2}$, razão do maior fracionamento magmático e consequentemente diminuição das suas concentrações nos líquidos mais diferenciados finais e empobrecimento de minerais ferromagnesianos.

Os valores de ítrio no diagrama $\mathrm{Y}$ vs $\mathrm{SiO}_{2}$ (Figura 9I) mostram uma correlação negativa para as fácies mais diferenciadas. Os valores decrescentes de ítrio são devido ao maior fracionamento magmático, e consequentemente ao empobrecimento de minerais ferromagnesianos.

Nos diagramas de caracterização de ambiente geotectônico observa-se na figura 10A (Batchelor \& Bowden, 1985), que as amostras são classificadas segundo um trend de distribuição, como pertencentes a um evento magmático sin-colisional a anorogênico.

No diagrama de caracterização de ambiente geotectônico observa-se nas figuras $10 \mathrm{~B}$ e C, (Pearce et al., 1984), que as rochas são classificadas como possivelmente pertencentes a uma suíte magmática de granitos sin- a póscolisionais de arco magmático a anorogênicos de ambiente de intraplaca. 

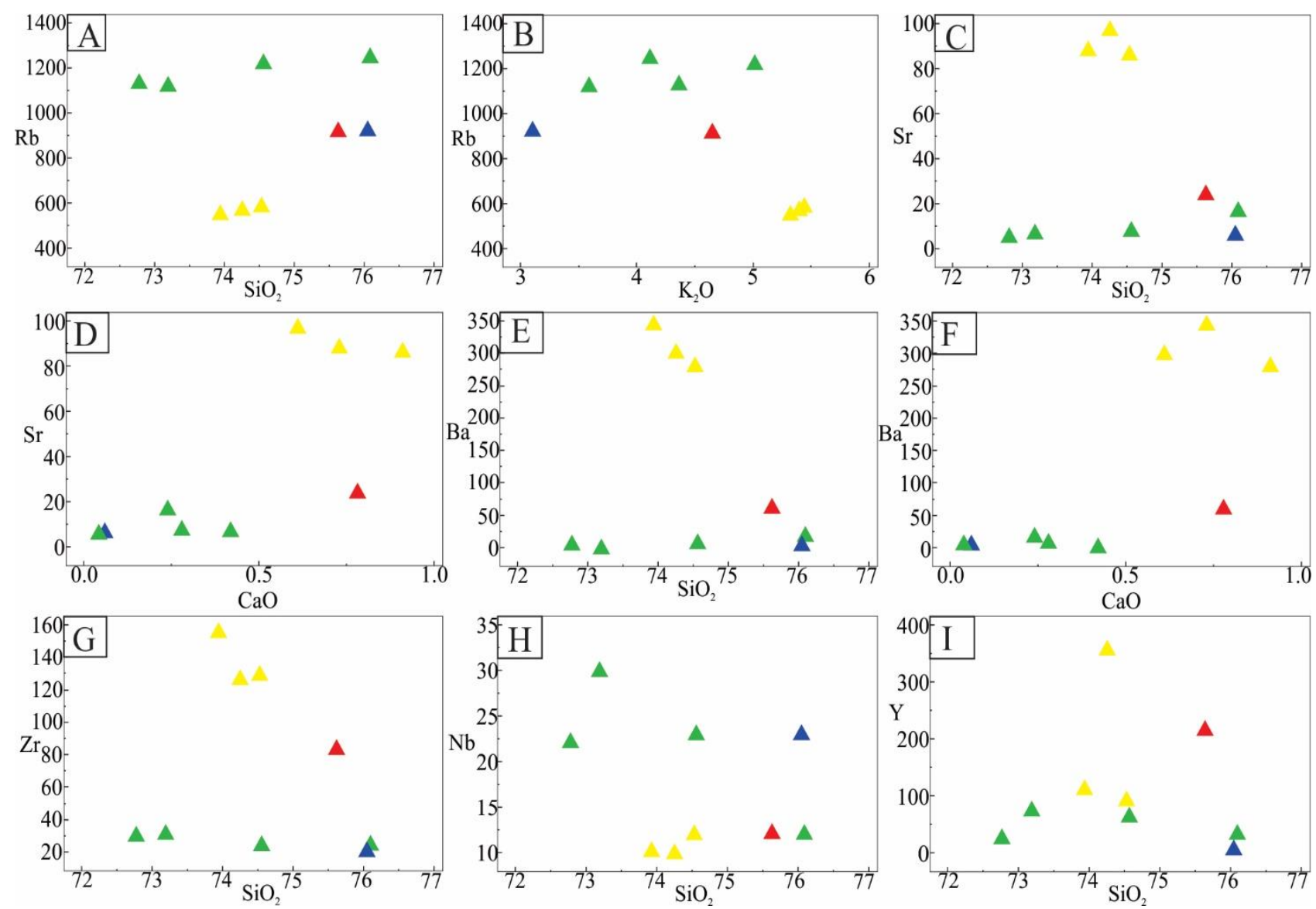

Figura 9. Diagramas binários para elementos traços das rochas do Granito Correas.

No diagrama da figura 10D, (Whalen et al., 1987), o resultado obtido reforça este caráter das rochas compatíveis e transicionais entre o campo dos granitos do tipo I, para granitos tipo A, que condiz com os litotipos mais tardios e mais diferenciados, os albita granitos.

No diagrama de classificação com base nas condições de oxidação (Figura 10E) proposto por Frost et al. (2001) as amostras se apresentam dominantemente no campo de granitos ferrosos do tipo I caledonianos de Pitcher (1983) de alto potássio e pós-tectônico e os granitos do tipo A.

No diagrama de Dall'Agnol \& Oliveira (2007) com base nas condições de oxidação (Figura 10F), as amostras se agrupam no campo dos granitos do tipo A reduzidos com exceções das amostras de albita granito.

Nos diagramas de Eby (1992) das figuras 10 $\mathrm{G}$ e $\mathrm{H}$, as amostras classificam-se como granitos do tipo A no campo A2, sugerido para granitos pós-orogênicos a anorogênicos de ambiente intraplaca, gerados a partir da fusão de material da crosta, ambiente comum também à geração dos granitos rapakivis.

As fases magmáticas iniciais do corpo granítico encontram-se vinculadas a ambientes de arco de ilha (IAB).
Nos diagramas de Whalen et al. (1987) as amostras analisadas são classificadas como granito do tipo A (Figura 11), embora grande parte das amostras se encontre na linha de transição entre granitos tipo I e A.

Nos variogramas de multielementos, os elementos traços estão normalizados segundo os valores de Thompson (1982) para meteoritos condríticos (Figura 12A) e segundo os valores de Weaver \& Tarney (1984) para crosta inferior (Figura 12B).

Observa-se um empobrecimento de $\mathrm{Ba}, \mathrm{Sr}, \mathrm{Ti}$ e $\mathrm{Y}$ em todos os litotipos, sendo a fácies micaalbita granito a mais empobrecida.

Os diagramas de elementos terras raras (ETR) foram normalizadas segundo os valores de meteoritos condríticos de Boynton (1984) (Figura 12C) e também normalizadas segundo os valores para crosta inferior Weaver \& Tarney (1984) (Figura 12D).

O padrão de fracionamento resultante da composição de ETRT (total) observado (Figura 12C, 12D), demonstra uma fraca assimetria, definida por um fraco enriquecimento em ETR leves (ETRL), em relação aos ETR pesados (ETRP), constituindo um padrão sub-horizontal e forte anomalia negativa de európio (Eu). 

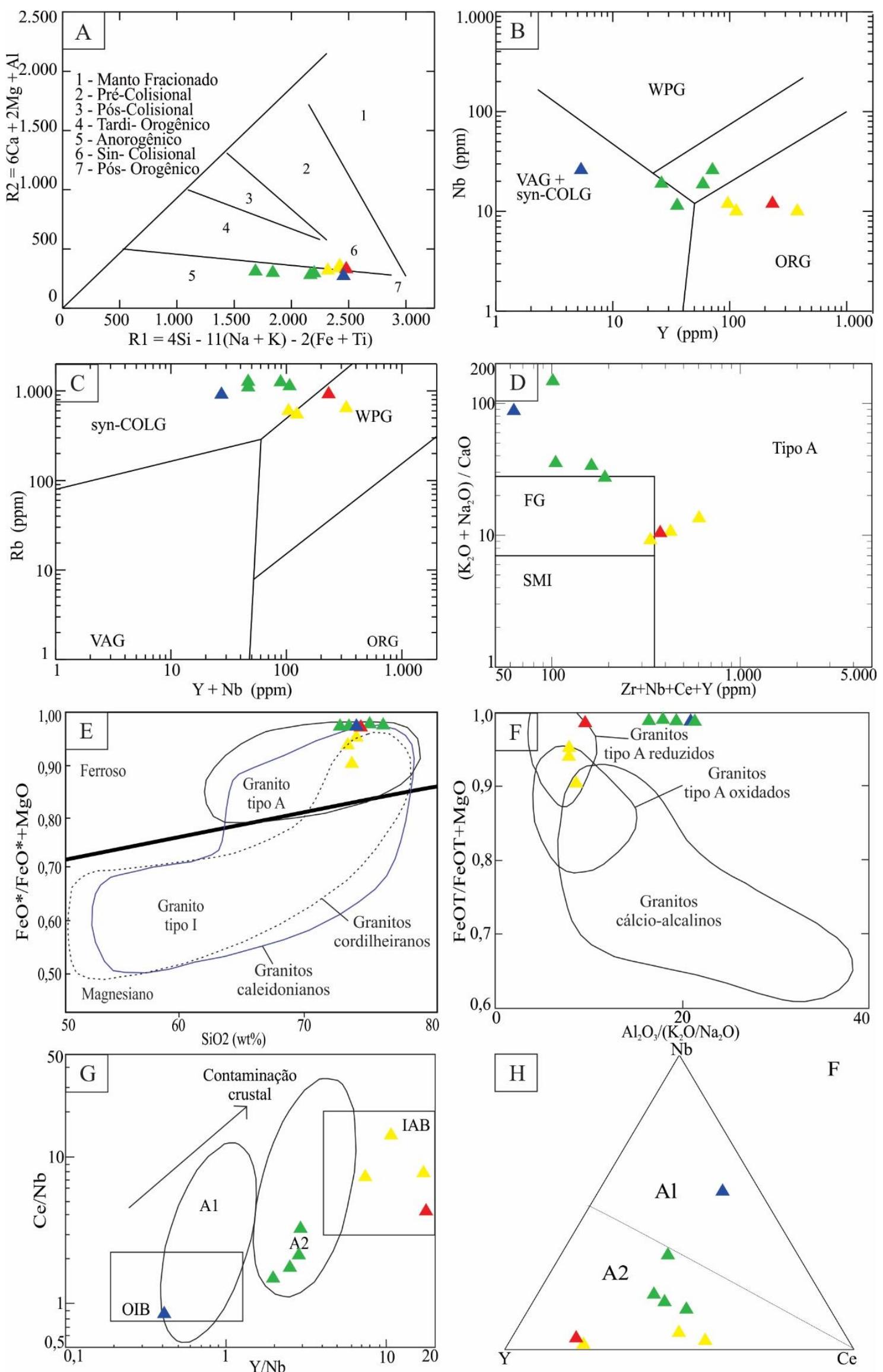

Figura 10 - Diagramas geoquímicos de ambientes tectônicos para elementos traços. A) Batchelor \& Bowden (1985); B e C) Pearce et al. (1984) (Syn-COLG) granitoide sin-colisional; (VAG) granitoide de arco vulcânico; (WPG) granitoide intraplaca; (ORG) granitoides de cadeias oceânicas; D) Whalen et al. (1987) - S M I: médias composicionais dos granitos dos tipos S, M e I; FG: granitos félsicos fracionados; E) Frost et al. (2001), F) Dall'Agnol, \& Oliveira (2007); G e H) Eby (1992) -OIB: Ilha Oceânica; IAB: Arco de Ilha; A1: granitos do tipo A de origem mantélica e A2: granitos do tipo A de origem crustal. 

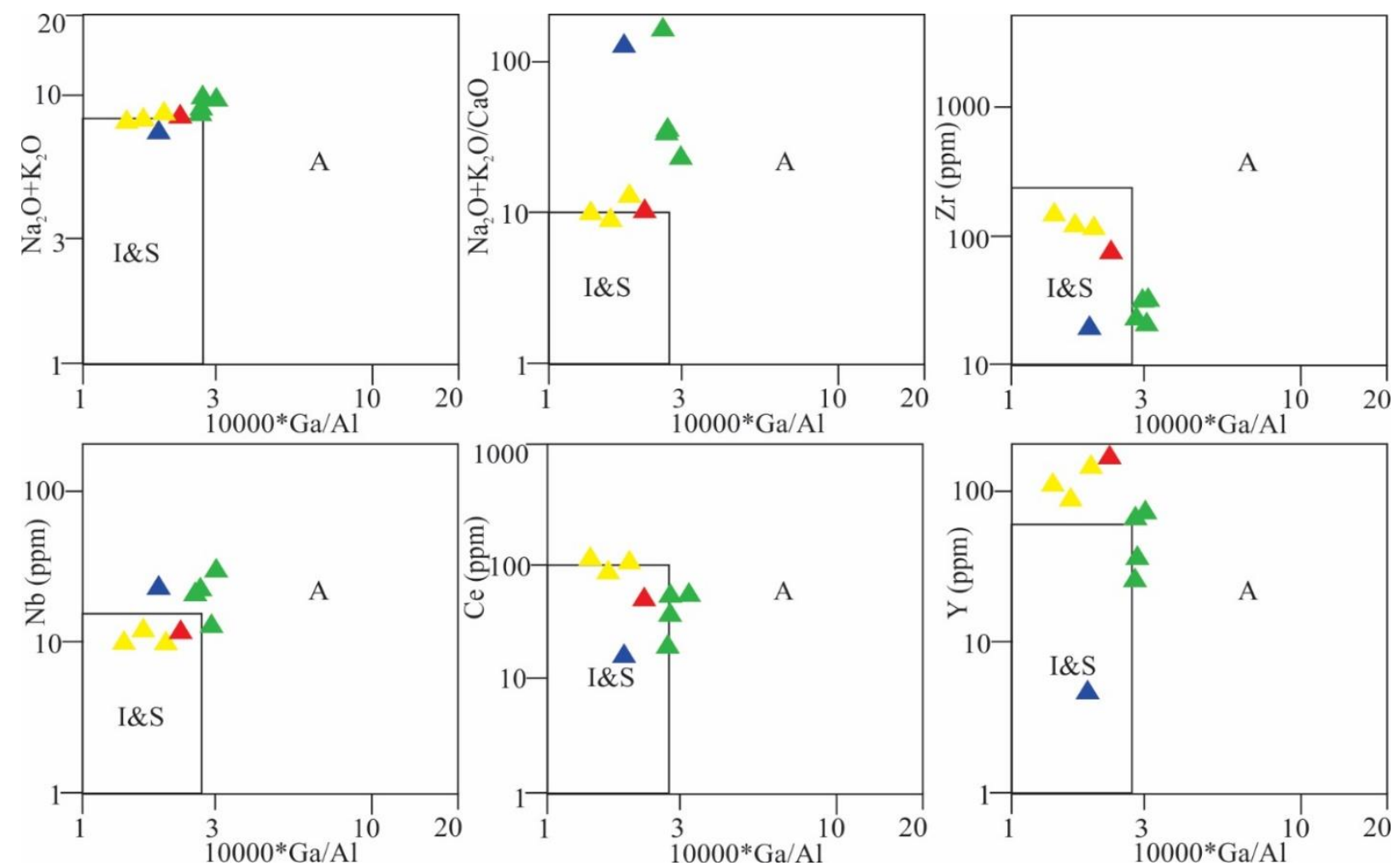

Figura 11 - Diagramas de classificação de Whalen et al. (1987). S \& I: médias composicionais dos granitos dos tipos S, e I; A: granitos do tipo A.
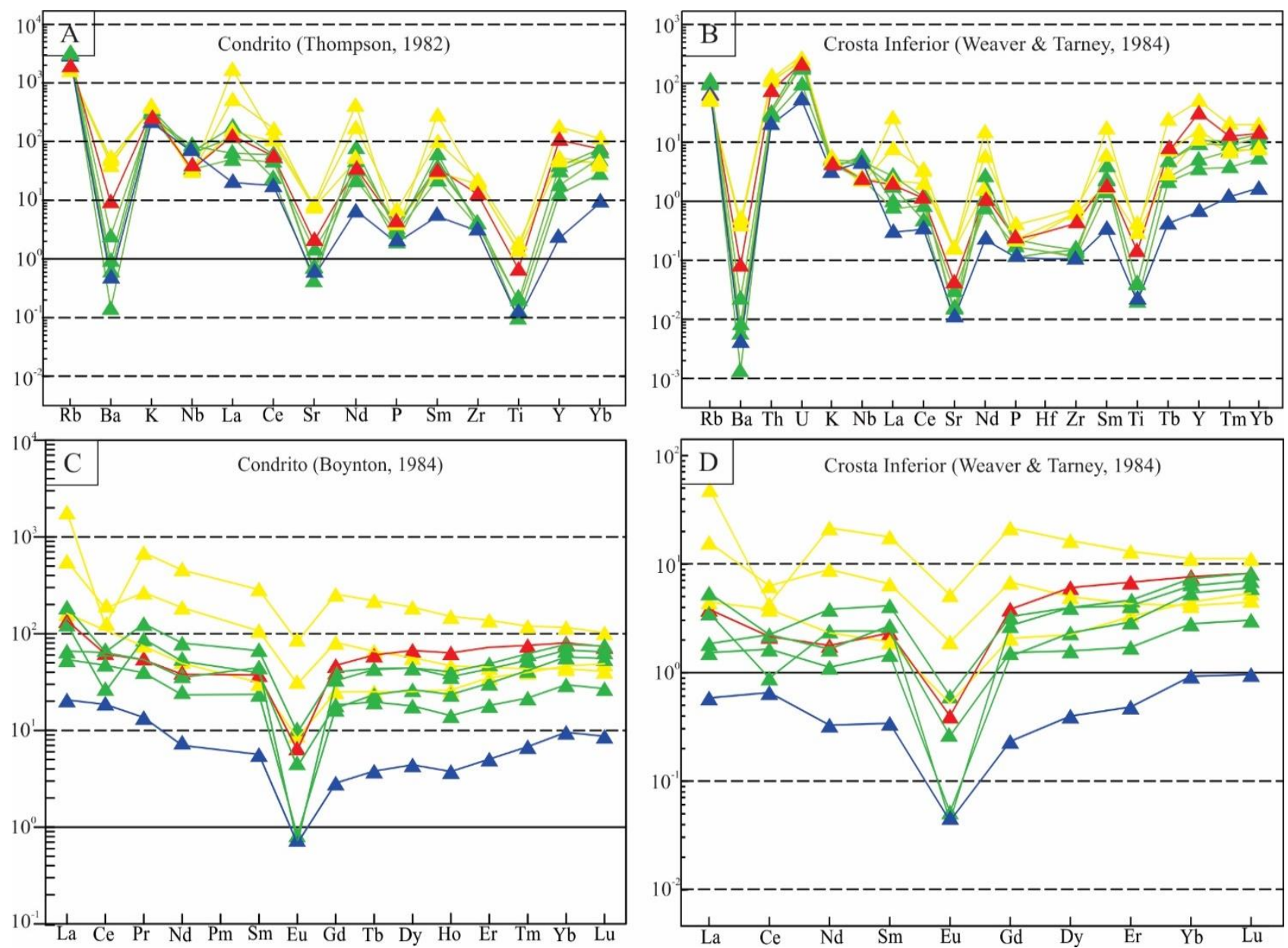

Figura 12 - Diagramas de variogramas de multielementos incompatíveis e elementos terra raras para as amostras de rochas do Granito Correas. Elementos incompatíveis normalizados: A) Valores para meteoritos condríticos de Thompson (1982) e B) Valores da crosta inferior de Weaver \& Tarney (1984). Elementos terras raras normalizados: C) Valores dos meteoritos condríticos de Boynton (1984) e D) Valores da crosta inferior de Weaver \& Tarney (1984). 
São observados pelo menos dois padrões distintos:

O biotita monzogranito que constitui as rochas iniciais do stock e apresenta um padrão mais diferenciado e enriquecido em ETRT, uma assimetria maior imposta pelo acréscimo dos ETRL, evidenciado por uma razão média $\mathrm{La} / \mathrm{Yb}=$ $>10,66, \mathrm{Eu}^{*}=201,51, \mathrm{Eu} / \mathrm{Eu}^{*}=0,20$, e mostra uma distribuição com fraco enriquecimento em ETR leves (ETRL) (razão $\mathrm{Ce}-\mathrm{Sm}=1,87$ ) em relação aos ETR pesados (ETRP) (razão Gd-Yb= 1,53). E o mica-albita granito que constitui as rochas finais do stock e apresenta um padrão menos enriquecido em ETRT e uma menor assimetria entre ETRL e ETRP, este padrão está definido por uma (razão média $\mathrm{La} / \mathrm{Yb}>2,20$ ), $\mathrm{Eu}^{*}=57,13, \mathrm{Eu} / \mathrm{Eu}^{*}=0,06 \mathrm{e}$, mostra uma distribuição com fraco enriquecimento em ETR leves (ETRL) (razão $\mathrm{Ce}-\mathrm{Sm}=1,26)$ em relação aos ETR pesados (ETRP) (razão Gd-Yb=0,48).

\section{CONCLUSÕES}

O Maciço Correas com aproximadamente 5 $\mathrm{km}^{2}$, ocorre sob a forma de um stock granítico alongado na direção ENE-WSW, paralelo a direção NE-SW das principais zonas de cisalhamento e que pode ser subdivido em 3 fácies principais denominadas: biotita monzogranito porfirítico, biotita-muscovita sienogranito porfirítico e mica-albita granito porfirítico com topázio. As amostras das duas primeiras fácies foram interpretadas como pertencentes a mesma fase magmática primária, menos diferenciada. A fácies mica-albita granito possui grandes diferença químicas e mineralógicas em relação as outras duas fácies, e foi interpretada como representante de uma fase secundária, mais tardia e evoluída do sistema e está associado a ocorrência de greisens mineralizados em cassiterita e volframita.

As análises de química mineral confirmaram o caráter sódico dos plagioclásios na fácies mais fracionada e indicam variação química da composição das micas conforme o fracionamento progressivo das fácies, sendo que na fácies mais evoluída a mica predominante é zinnwaldita.

As análises litogeoquímicas mostram que as rochas do maciço se distribuem sob dois padrões: as rochas iniciais do stock são pertencentes às séries cálcio-alcalinas alto potássio a shoshonítica, de caráter peraluminoso; o segundo padrão geoquímico são as das rochas definidas pelo magma residual de composição mais sódica constituindo na série alcalina sódica magmática.

Este magmatismo é compatível com granito do tipo A, rapakivi e pós-colisional a anorogênico, associado a ambientes intraplaca ou associado a ambiente sin- a pós-colisional de arco magmático, correlacionado a estruturas transtensivas de zonas de cisalhamento, em um ambiente extensional ao final do evento colisional da Orogênese Ribeira.

\section{AGRADECIMENTOS}

Os autores externam seus agradecimentos a Empresa Minerais e Metais Comércio e Indústria Ltda., que opera a lavra e ao CNPq pelo apoio do processo $\mathrm{n}^{\circ}: 304.614 / 2017-3$.

\section{REFERÊNCIAS}

ALMEIDA, F.F.M. Novas ocorrências de fósseis no PréCambriano brasileiro. Anais da Academia Brasileira de Ciências, v. 29, n. 1, p. 63-72, 1957.

ALMEIDA, F.F.M. Origem e evolução da Plataforma Brasileira. Rio de Janeiro. Boletim DNPM/DGM, v. 36, p. 241, 1967.

ALMEIDA, F.F.M.; HASUI, Y.; BRITO NEVES, B.B.; FUCK, R.A. Províncias estruturais brasileiras. In: SIMPÓSIO DE GEOLOGIA DO NORDESTE, 8, 1977, Campina Grande. Anais...Campina Grande: Sociedade Brasileira de Geologia, 1977, p. 363-391.

ALMEIDA, F.F.M.; HASUI, Y.; PONÇANO, W.L.; DANTAS, A.S.L.; CARNEIRO, C.D.R.; MELO, M.S.; BISTRICH, C.A Mapa Geológico do estado de São Paulo em escala 1:500.000. Nota explicativa. São Paulo, IPT, Monografias 6, v. 1,126 p., 1981.

BATCHELOR, R.A. \& BOWDEN, P. Petrogenetic interpretation of granitc rock series using multicationic parameters. Chemical Geology, v. 48, p. 43-55, 1985.

BITTENCOURT, M.F. \& NARDI, L.V.S. Late to postcollisional brasiliano granitic magmatism in southernmost
Brazil. Anais da Academia Brasileira de Ciência, v. 65, n. supl. 1, p. 3-16, 1993

BOYNTON, W.V. Geochemistry of the rare earth elements: meteorite studies. In: HENDERSEN, P. (Coords). Rare earth element geochemistry. Elsevier Amsterdam, p. 63-114, 1984.

CAMPANHA, G.A.C. Tectônica proterozoica no Alto e Médio Vale do Ribeira, Estados de São Paulo e Paraná. São Paulo, 1991. 296p. Tese (Doutorado), Instituto de Geociências Universidade de São Paulo.

CAMPANHA, G.A.C. O papel do sistema de zonas de cisalhamento transcorrentes na configuração da porção meridional da Faixa Ribeira. São Paulo, 2002. 105p. Tese (Livre Docência), Instituto de Geociências - Universidade de São Paulo.

CAMPANHA, G.A.C. \& SADOWSKI, G.R. Tectonics of the Southern Portion of the Ribeira Belt (Apiaí Domain). Precambrian Research, v. 98, p. 31-51, 1999.

CAMPANHA, G.A.C.; FALEIROS, F.M.; BASEI, M.A.S.; TASSINARI, C.C.G.; NUTMAN, A.P.; VASCONCELOS, P.M. Geochemistry and age of mafic rocks from the Votuverava 
Group, southern Ribeira Belt, Brazil: Evidence for 1490Ma oceanic back-arc magmatism. Precambrian Research, v. 266, p. 530-550, 2015.

CORDANI, U.G.; DELHAL, J.; LEDENT, O. Orogenèses superposeés dans le Précambrien du Brésil sud-oriental (États du Rio de Janeiro et de Minas Gerais). Revista Brasileira de Geociências, v. 3, n. 1, p. 1-22, 1973.

CORDANI, U.G.; SATO, K.; TEIXEIRA, W.; TASSINARI, C.C.G.; BASEI, M.A.S. Crustal evolution of the South American platform. In: CORDANI, U.G.; MILANI, E.J.; THOMAZ FILHO, A.; CAMPOS, D.A. (Eds.) Tectonic evolution of South America, Rio de Janeiro: p. 19- 40, 2000.

DALL'AGNOL, R. \& OLIVEIRA, D.C. Oxidized, magnetiteseries, rapakivi-type granites of Carajás, Brazil: Implications for classification and petrogenesis of A-type granites. Lithos v. 93, p. 215-233, 2007.

DEBON, F. \& LE FORT, P. A chemical-mineralogical classification of common plutonic rocks and associations. Transactions of the Royal Society of Edinburgh Earth Sciences, v. 73, p. 135-149, 1983.

DEBON, F.; LE FORT, P.; SABATÉ, P. Uma classificação químico-mineralógica das rochas plutônicas comuns e suas associações, método e aplicações. Revista Brasileira de Geociências. v. 18, n. 2, p. 122-133, 1988.

DEER, W.A.; HOWIE, R.A.; ZUSSMAN, J. Rock forming minerals. Londres, Longman, 558 p., 1963.

EBY, G.N. Chemical subdivision of the A-type granitoids: Petrogenetic and tectonic implications. Geology, v. 20, p. 641644, 1992

El BOUSEILY, A.M. \& El SOKKARY, A.A. The Relation between $\mathrm{Rb}, \mathrm{Ba}$ and $\mathrm{Sr}$ in Granitic Rocks. Chemical Geology, v. 16, p. 207-219, 1975.

FALEIROS, F.M. Evolução de terrenos tectono-metamórficos da Serrania do Ribeira e Planalto Alto Turvo (SP, PR). São Paulo, 306 p. 2008. Tese (Doutorado em Geoquímica e Geotectônica), Instituto de Geociências da Universidade de São Paulo.

FALEIROS, F.M.; CAMPANHA, G.A.C.; BELLO, R.M.S.; FUZIKAWA, K. Quartz recrystallization regimes, c-axis texture transitions and fluid inclusion reequilibration in a prograde greenschist to amphibolite facies mylonite zone (Ribeira Shear Zone, SE Brazil). Tectonophysics, v. 485, p. 193-214, 2010.

FALEIROS, F.M.; CAMPANHA, G.A.C.; MARTINS, L.; VLACH, S.R.F.; VASCONCELOS, P.M. Ediacaran highpressure collision metamorphism and tectonics of the southern Ribeira Belt (SE Brazil): evidence for terrane accretion and dispersion during Gondwana assembly. Pre-cambrian Research, v.189, n. 3-4, p. 263-291, 2011.

FIORI, A.P. Tectônica e estratigrafia do Grupo Açungui a norte de Curitiba. São Paulo, 1990. 261p. Tese (Livre Docência). Instituto de Geociências, Universidade de São Paulo.

FIORI, A.P. Tectônica e estratigrafia do Grupo Açungui, PR. Boletim IG-USP. Série Científica, v. 23, p. 55-74, 1992.

FIORI, A.P. Evolução geológica da bacia Açungui. Boletim Paranaense de Geociências, v. 42, p. 7-27, 1994

FRASCÁ, M.H.B.O.; FIGUEIREDO, M.C.H.; ALMEIDA, M.A.; COUTINHO, J.M.V. Petrografia e geoquímica da Formação Água Clara, região de Araçaíba, SP. Boletim IGUSP. Serie Científica, v. 21, p. 73-92, 1990.

FROST, B.R.; BARNES, C.G.; COLLINS, W.J.; ARCULUS, R.J.; ELLIS, D.J.; FROST, C.D. A geochemical classification for granitic rocks. Journal of Petrology, v. 40, p. 261-293 2001.

FUCK, R.A.; MARINI, O.J.; TREIN, E. Contribuição ao estudo das rochas graníticas do Estado do Paraná. Boletim Paranaense de Geociências, v. 23, p. 183-221, 1967.

GIMENEZ FILHO, A. Evolução do Complexo Granítico Três Córregos a noroeste da Apiaí - SP. São Paulo, 1993, 118 p. Dissertação (Mestrado), Instituto de Geociências
Universidade de São Paulo.

GIMENEZ FILHO, A.; TEIXEIRA, W.; FIGUEIREDO, M.C.; TREVIZOLI JÚNIOR, L.E. Geologia, Petrografia e Litogeoquímica do Complexo Granítico Três Córregos na Região de Barra do Chapéu e Ribeirão Branco, SP. São Paulo. Revista Brasileira de Geociências, v. 25, n. 2, p. 92-106, 1995. GODOY, A.M. Caracterização Faciológica, Petrográfica e Geoquímica dos Maciços Sorocaba e São Francisco, SP. São Paulo, 1989. 221 p. Tese (Doutorado), Instituto de Geociências, Universidade de São Paulo.

GODOY, A.M. Estudos Geológicos das Rochas Granitóides e Metamórficas e suas Aplicações como Rochas Ornamentais e de Revestimento. Rio Claro, 2003. 243 p. Tese (Livre Docência), Instituto de Geociências e Ciências Exatas, Universidade Estadual Paulista.

GORAIEB, C.L. Aspectos geológicos e metalogenéticos do Maciço Correas. São Paulo, 1995. Dissertação (Mestrado), Instituto de Geociências - Universidade de São Paulo.

GORAIEB, C.L. Contribuição à Gênese do Depósito Primário Polimetálico ( $\mathrm{Sn}, \mathrm{W} \pm, \mathrm{Zn}, \mathrm{Cu}, \mathrm{Pb})$ Correas, Ribeirão Branco (SP). São Paulo, 2001. Tese (Doutorado), Instituto de Geociências - Universidade de São Paulo.

GORAIEB, C.L. \& OLIVEIRA, M.C.B. Aspectos da geologia e prospecção da área do granito Correas e mineralizações estanotungsteníferas associadas. Revista da Escola de Minas, v. 3, n. 2, p. 57-69, 1990.

GORAIEB, C.L.; MELLO, I.S.C.; SILVA, R.B. Geologia e prospecção da área do Bairro dos Correias, Município de Ribeirão Branco (SP). In: SIMPÓSIO REGIONAL DE GEOLOGIA, 6, Rio Claro, 1987. Atas...Rio Claro: Sociedade Brasileira de Geologia, 1987, v. 2, p. 491-502.

GORAIEB, C.L.; OLIVEIRA, M.C.B.; MELLO, I.S.C.; SILVA R.B. As mineralizações estano-tungsteníferas do Granito Correas (SP). In: CONGRESSO LATINOAMERICANO DE GEOLOGIA, 7, Belém, 1988. Anais ... Belém: Sociedade Brasileira de Geologia, 1988, p. 154-172.

GUIMARÃES, G.B. As rochas granitóides do complexo granítico Cunhaporanga, Paraná: aspectos geológicos, geofísicos, geoquímicos e mineralógicos. São Paulo, 2000, 230p. Tese (Doutorado), Instituto de Geociências Universidade de São Paulo.

HARKER, A. The Natural History of Igneous Rocks. London, Methuen, 384 p., 1909.

HASUI, Y. A grande Colisão Pré-Cambriana do Sudeste brasileiro e a Estruturação Regional. São Paulo, UNESP, Geociências, v. 29, n. 2, p. 141-169, 2010.

HASUI, Y. \& OLIVEIRA, M.A.F. Província Mantiqueira. Setor Central. In: ALMEIDA, F.F. \& HASUI, Y. (Eds). O Précambriano do Brasil. São Paulo, p. 308-344, 1984.

HASUI, Y.; CARNEIRO, C.D.R.; BISTRICHI, C.A. Os Granitos e Granitóides da Região de Dobramentos Sudeste nos Estados de São Paulo e Paraná. In: CONGRESSO BRASILEIRO DE GEOLOGIA, 30, 1978, Recife. Anais...Recife: Sociedade Brasileira de Geologia, 1978, p. 2579-2593.

HASUI, Y. Sistema Orogênico Mantiqueira. In: HASUI, Y., CARNEIRO, C.D.R., ALMEIDA, F.F.M.A., BARTORELLI, A. (org.) Geologia do Brasil. São Paulo, Beca, p. 331- 372, 2012.

HEILBRON, M.; VALERIANO, C.M.; VALLADARES, C.S.; MACHADO, N.A Orogênese Brasiliana no segmento central da Faixa Ribeira, Brasil. Revista Brasileira de Geociências, v. 25, n. 4, p. 249-266, 1995.

HEILBRON, M.; SOARES, A.C.P.; CAMPOS NETO, M.C.; SILVA, L.C.; TROUW, R.A.J.; JANASI, V.A. Província Mantiqueira. In: Geologia do continente Sul-americano: evolução da obra de Fernando Flávio Marques de Almeida. São Paulo, Ed. DECA, 2004, p. 203-234.

HEY, M.H. A new review of the chlorites. The Mineralogical Magazine, v. 30, p. 277-292, 1954.

JANASI, V.A. \& ULBRICH, H.H.G.J. Inventário Bibliográfico de Granitos do Estado de São Paulo. Boletim Instituto de

628 São Paulo, UNESP, Geociências, v. 39, n. 3, p. 609 - 630, 2020


Geociências. Publicação Especial, v. 11, 253 p. 1992.

KOPS, P.T. Geologia das Formações Antinha, Votuverava e Água Clara à sudeste do Complexo Granítico Três Córregos, Estado do Paraná. Rio Claro, 1994, 132 p. Dissertação de Mestrado, Instituto de Geociências Universidade Estadual Paulista.

LAMEYRE, J. \& BOWDEN, P. Plutonic Rock Types Series: Discrimination of Various Granitoids Series and Related Rocks. Journal of Volcanology and Geothermal Research v. 14, n. 1-2, p. 169-186, 1982.

MALAGUTTI, M.I.A.; BAHIA FILHO, O.; MORENO, M.M.T.; NARDY, A.J.R. Determinação de elementos terras raras e ítrio em rochas silicáticas por ICP-AES com separação em resina trocadora de íons. Geochimica Brasiliensis, v. 12, n. 2, p. 7580, 1998.

MANIAR, P.D. \& PICOLLI, P.M. Tectonic Discrimination of Granitoids. Geological Society of America Bulletin, v. 101, p. 635-643, 1989.

MATA, S. P. Petrografia, Geoquímica e Química Mineral do Granito Correas associado as mineralizações de estanho, SW do estado de São Paulo. Rio Claro, 2019. 93 p. Trabalho (Conclusão de Curso), Instituto de Geociências e Ciências Exatas, Universidade Estadual Paulista.

MATA, S.P.; VIEIRA, O.A.R.P.; GODOY, A.M. Geologia do Maciço Correas, Sudeste do Estado de São Paulo. Unesp, Geociências, v. 39, n. 2, p. 297-316, 2020.

MIDDLEMOST, E.A.K. Magmas and magmatic rocks. Longman, London, 1985. system $\mathrm{K} 2 \mathrm{O}-\mathrm{MgO}-\mathrm{FeO}-\mathrm{Al} 2 \mathrm{O} 3-\mathrm{SiO} 2-\mathrm{H} 2 \mathrm{O}$ : an experimental study at $2 \mathrm{Kbar} \mathrm{PH} 2 \mathrm{O}$ and comparison with natural $\mathrm{Li}$-free white micas. Mineralogical Magazine, v. 50, p. 257-266, 1986a.

MONIER, G. \& ROBERT, J. Evolution of the miscibility gap between muscovite and biotite solid solutions with increasing lithium content: an experimental study in the system K2O$\mathrm{Li} 2 \mathrm{O}-\mathrm{MgO}-\mathrm{FeO}-\mathrm{Al} 2 \mathrm{O} 3-\mathrm{SiO} 2-\mathrm{H} 2 \mathrm{O}-\mathrm{HF}$ at $600^{\circ} \mathrm{C}, 2 \mathrm{Kbar}$ PH2O: comparison with natural lithium micas. Mineralogical Magazine, v. 50:641-651, 1986b.

MULLER, A. \& SELTMANN, R. The genetic significance of snowball quartz in highly fractionated tin granites of the Krušné Hory Erzgebirge. Stanley, C.J. (Ed.) BIENNIAL SGA MEETING, $5^{\text {th }}$. London, Abstract Volume... London: CRC Press, p. 409-412, 1999.

PEARCE, J.A.; HARRIS, N.B.W.; TINDLE, A.G. Trace Element Discrimination Diagrams for the Tectonic Interpretation of Granitic Rocks. Journal of Petrology, v. 25, p. 956-983, 1984

PEREIRA, R.M.; NEUMANN, R.; ÁVILA, C.AL.; CASTRO, C. Determinação da gênese da cassiterita com base na sua composição química e inclusões minerais: ocorrências no sul e sudeste brasileiro. Revista Brasileira de Geociências, v. 38, n

PEREIRA, R.M.; NEUMANN, R.; NETTO, A.M. Cassiterita magnética do depósito do Bairro dos Correas, Ribeirão Branco, SP. In: SIMPÓSIO DE GEOLOGIA DO SUDESTE, 7, Rio de Janeiro, 2001. Anais... Rio de Janeiro: Sociedade Brasileira de Geologia, 2001, p. 99

PEREIRA, R.M.; ÁVILA, C.A.; NEUMANN, R.; BARRUETO, H.R. Estudo químico de grãos de cassiterita e implicação com a paragênese do depósito polimetálico do Bairro dos Correas, São Paulo. In: SIMPÓSIO DE GEOLOGIA DO SUDESTE, VIII, 2003, São Pedro. Anais...São Pedro: Sociedade Brasileira de Geologia, 2003.

PETRI, S. \& SUGUIO, K. Sobre os metassedimentos do grupo Açungui do extremo sul do estado de São Paulo. São Paulo. Secretaria de Serviços e Obras Públicas/Faculdade de Filosofia, Ciências e Letras da USP, p. 1-98, 1969.

PITCHER, W.S. Granite type and tectonic environment. In: HSU KENETH, J. (ed.) Mountain building processes. Acad. Press. London. chap. I- 3, p. 19-40, 1983.

PRAZERES FILHO, H.J. Caracterização geológica e
MONIER, G. \& ROBERT, J. Muscovite solid solutions in the 2, p. 246-252, 2008.

petrogenética do Batólito Granítico Três Córregos (PRSP) geoquímica isotópica (Nd-Sr-Pb), idades (ID-TIMS/ SHRIMP) e $\delta 180$ em zircão. São Paulo, 2005. 207 p. Tese (Doutorado) - Instituto de Geociências, Universidade de São Paulo.

PRAZERES FILHO, H.J.; HARARA, O.M.; BASEI, M.A.S.; PASSARELLI, C.R.; SIGA JR, O. Litoquímica, geocronologia $\mathrm{U}-\mathrm{Pb}$ e geologia isotópica ( $\mathrm{Sr}-\mathrm{Nd}-\mathrm{Pb}$ ) das rochas graníticas dos batólitos Cunhaporanga e Três Córregos na porção sul do Cinturão Ribeira, Estado do Paraná. Boletim IG-USP/ Série Científica, São Paulo, v. 3, p. 51-70, 2003.

PRESSINOTTI, P.C.; HASUI, Y.; SILVA, R.B.; STEFANI, F.L.; TRINDADE, M.; COSTA, M.O. Análise De Lineamentos Na Exploração Mineral: Aplicação No Sudeste Paulista. Revista IG, São Paulo, v. 13, n. 2, p. 17-29, 1992

SANTOS, T.M.B.; TASSINARI, C.C.G; FONSECA, P.E. Diachronic collision, slab break-off and long-term high thermal flux in the Brasiliano-Pan-African orogeny: Implications for the geodynamic evolution of the Mantiqueira Province. Precambrian Research, v. 260, p. 1-22, 2015.

SILVA, R.B. Distinção de fertilidade para Sn e W em granitóides do sul de São Paulo. Rio Claro, 1995, Tese (Doutorado), Instituto de Geociências e Ciências Exatas, Universidade Estadual Paulista.

SILVA, R.B. \& ETCHEBEHERE, M.L.C. Contribuição ao estudo da potencialidade tungstenífera do Estado de São Paulo e critérios de prospecção. In: CONGRESSO BRASILEIRO DE GEOLOGIA, 34, Goiânia, 1986. Anais... Goiânia: Sociedade Brasileira de Geologia, 1986, v.5, p.

SILVA, R.B. \& PRESSINOTTI, P.C. Proposição de um modelo de exploração para mineralizações de estanho e tungstênio em granitóides do Estado de São Paulo. Revista Instituto de Geociências, n. 1-2, p. 55-66, 1991.

SPEER, J.A. Micas in igneous rocks. In: BAILEY, SW. (eds.) Micas. Review in Mineralogy, 13, Washington. Mineralogical Society of America, p. 299-356, 1984.

TASSINARI, C.C.G.; BARBOUR, A.P.; DAITX, E.C.; SATO, $\mathrm{K}$. Aplicação dos isótopos de $\mathrm{Pb}-\mathrm{Sr}$ na determinação da natureza das fontes das mineralizações de chumbo do Vale do Ribeira - SP e PR. In: CONGRESSO BRASILEIRO DE GEOLOGIA, 36, 1990, Natal. Anais... Natal: Sociedade Brasileira de Geologia, n. 3, p. 1254-1266, 1990.

TAYLOR, W.P. Intrusion and differentiation of granitic magma at high level in the crust: the Puscao Pluton. Lima, Peru. Journal of Petrology, v. 17, n. 2, p. 194-218, 1976.

THEODOROVICZ, A; CÂMARA, M.M.; MORAES, S.M; GODOY, H.K.; TAKAHASHI, A.T. Projeto Engenheiro Maia-Ribeirão Branco: Relatório Final. São Paulo. Contrato CPRM/PROMINÉRIO. 2 v., 1986.

THEODOROVICZ, A.; CÂMARA, M.M.; TAKAHASHI, A.T.; MORAES, S.M.; GODOY, H.K. Geologia do Pré-Cambriano das Folhas Engenheiro, Maia e Ribeirão Branco, São Paulo. In: CONGRESSO BRASILEIRO DE GEOLOGIA, 35, Belém, 1988. Anais...Belém: Sociedade Brasileira de Geologia, 1988, v. 6, p. 2713-2726.

THOMPSON, R.N. British Tertiary volcanic province. Journal of Geology, v. 18, p. 49-107, 1982.

TINDLE, A.G. \& WEBB, P.C. Estimation of lithium contents in trioctahedral micas using microprobe data: application to micas from granitic rocks. European Journal of Mineralogy, v. 2, p. 595-610, 1990.

TISCHENDORF, G.; RIEDER， M.; GOTTESMANN， B.; GUIDOTTI, C.V. A new graphical presentation and subdivision of potassium micas. Mineralogical Magazine, v. 68, p. 649-667, 2004.

TISCHENDORF, G.; FÖRSTER, H.J.; GOTTESMANN, B.; RIEDER, M. True and brittle micas: composition and solidsolution series. Mineralogical Magazine, v. 71, p. 285-320, 2007.

VLACH, S.R.F.; JANASI, V.A.; VASCONCELLOS, A.C.B.C. The Itu Belt: associated calk alkaline and aluminous a-type late

São Paulo, UNESP, Geociências, v. 39, n. 3, p. 609 - 630, 2020 
Brasiliano granitoids in the states of São Paulo and Paraná, southern Brazil. In: CONGRESSO BRASILEIRA DE GEOLOGIA, 36, 1990, Natal. Anais...Natal: Sociedade Brasileira de Geologia, v. 4, p. 1700-1711, 1990.

WEAVER, B. \& TARNEY, J. Empirical approach to estimating the composition of the continental crust. Nature, v. 310, p. 575$57,1984$.

WERNICK, E.; GALEMBECK, T.M.B.; GODOY, A.M.; HERMANN, P.K. Geochemical variability of the Rapakivi Itu Province, State of São Paulo, SE Brazil. Anais da Academia Brasileira de Ciências, v. 69, n. 3, p. 395-413, 1997.

WERNICK, E. Arc-related Rapakivi Granites from the Ribeira Fold Belt, SE Brazil. Revista Brasileira de Geociências, v. 30, n. 1 , p. $20-24,2000$.
WHALEN, J.W.; CURRIE, K.L.; CHAPPEL, B.W. A-Type Granites: Geochemical Characteristics, Discrimination and Petrogenesis. Contributions to Mineralogy and Petrology, v. 95, p. 407-419, 1987.
Submetido em 15 de abril de 2020 Aceito em 24 de agosto de 2020 